\title{
What Is Quality? An Integrative Framework of Processes and States
}

Quality is a central element in business strategy and academic research. Despite important research on quality, an opportunity for an integrative framework remains. The authors present an integrative framework of quality that captures how firms and customers produce quality (the quality production process), how firms deliver and customers experience quality (the quality experience process), and how customers evaluate quality (the quality evaluation process). The framework extends the literature in several ways. First, the authors describe important linkages between the three processes, including links reflecting the role of co-production. Second, they point to overlooked aspects of the quality processes that influence how quality is conceptualized and should be managed. These include customer heterogeneity in measurement knowledge and motivation; the role of emotion in quality production, experience, and evaluation; and a new typology of attributes. Third, they propose a quality state residing within each quality process and describe what gives rise to these states, which will enhance decision makers' ability to measure and manage quality processes. Finally, they offer theoretical and managerial implications derived from their integrative quality framework including 20 strategies to increase customer satisfaction.

Keywords: quality, service quality, perceived quality, satisfaction, expectations, emotion, co-production

Q uality is perhaps the most important and complex component of business strategy. Firms compete on quality, customers search for quality, and markets are transformed by quality. It is a key force leading to delighted customers, firm profitability, and the economic growth of nations (Deming 1982; Kennedy 1987; Rust, Zahorik, and Keiningham 1995). Given this breadth, quality has roots in business practice and in many disciplines including marketing, management, economics, engineering, operations, strategy, and consumer research.

In business practice, views of quality have evolved over the past 30 years through programs such as Total Quality Management, the Baldrige Awards, and Six Sigma, all of which have helped firms improve quality, particularly in manufactured goods (Deming 1982; Powell 1995). Academic research has also contributed to our understanding of quality. ${ }^{1}$ For example, marketing's explication of service

\footnotetext{
${ }^{1}$ Seminal contributions include how statistical quality control and process design improve production processes while reducing costs (e.g., Juran 1992; Shewhart 1986) and how customers' quality uncertainty and valuation may explain important market equilibria and determine optimal regulation levels (Akerlof 1970; Spence 1975).
}

Peter N. Golder is Professor of Marketing, Tuck School of Business, Dartmouth College (e-mail: peter.n.golder@tuck.dartmouth.edu). Debanjan Mitra is Associate Professor of Marketing, Warrington College of Business Administration, University of Florida (e-mail: deb.mitra@ warrington.ufl.edu). Christine Moorman is T. Austin Finch, Sr. Professor of Business Administration, Fuqua School of Business, Duke University (e-mail: moorman@ duke.edu). The authors thank Kusum Ailawadi, Joel Cohen, Kim Corfman, John Czepiel, Ed Holub, Jack Jacoby, Praveen Kopalle, Don Lehmann, Rich Lutz, Bob Shoemaker, Rick Staelin, Gerry Tellis, Bart Weitz, Russ Winer, Valarie Zeithaml, and, especially, Ajay Kohli and three anonymous JM reviewers for their insightful comments on previous versions of the article. quality has enhanced our understanding of perceived quality, customer expectations, and satisfaction (e.g., Boulding et al. 1993; Cronin and Taylor 1994; Oliver 1980; Parasuraman, Zeithaml, and Berry 1985, 1988; Zeithaml 1988). Quality continues to be a frequent focus of research in marketing and other disciplines. In fact, over the last five years, 79 articles on quality have been published in Journal of Marketing and Management Science.

Despite these advances, we believe that different perspectives on quality have resulted in an academic literature that is field-specific (Holbrook and Corfman 1985). For example, economics and industrial organization researchers view quality in terms of vertical product differentiation (e.g., Sutton 1986), whereas management researchers study quality in terms of organizational processes such as quality circles and total quality management (e.g., Powell 1995). In marketing, customers' perceptions of quality are paramount (Buzzell and Gale 1987; Parasuraman, Zeithaml, and Berry 1985). For example, Zeithaml (1988) defines "price, quality, and value from the customer's perspective" (p. 2) and notes that "objective quality may not exist because all quality is perceived by someone" (p. 5). In contrast, thought leaders in the quality management literature believe that perceived quality is just one of many dimensions of quality (Garvin 1984). Finally, in operations and engineering, quality means conformance to design specifications or the reliability of internal processes, even though many customers do not find these processes meaningful (Feigenbaum 1991; Juran 1992; Shewhart 1986). We believe that these different disciplinary perspectives hinder the development of a coherent body of knowledge, minimize knowledge transfer across disciplines, and cloud contributions to practice.

Different perspectives pervade research within marketing as well (Rust, Moorman, and Dickson 2002). As one 
example, scholars have proposed alternative quality frameworks for goods or services but not an integrated view of both (Brady and Cronin 2001; Brucks, Zeithaml, and Naylor 2000; Parasuraman, Zeithaml, and Berry 1988). In another example, quality has been operationalized as or used interchangeably with customer satisfaction (Fornell 1995; Karmarkar 1996) even though these concepts are distinct (Oliver 2009).

Given the lack of a common understanding across and within disciplines, it is not surprising that conceptual ambiguity about quality persists. On the basis of an exhaustive review of the quality literature, Reeves and Bednar (1994) conclude that "no universal, parsimonious, or all-encompassing definition or model of quality exists" (p. 436) and that "different definitions of quality are appropriate under different circumstances" (p. 419). More recently, Karmarkar and Apte (2007, p. 451) lament that "quality measurement and definition is a particularly complex issue.... A few specialized examples do exist. But is there a general template that would work for quality?" In some respects, these conclusions leave the study of quality at a crossroads not much different from Pirsig's (1974, pp. 260-1) observation made over 30 years ago in the cult novel Zen and the Art of Motorcycle Maintenance, "even though Quality cannot be defined, you know what Quality is!" (italics in original).

This article begins to address these limitations by providing a framework that integrates the aforementioned discipline-based perspectives. At the heart of this framework is a three-part process view of quality consisting of the quality production process, the quality experience process, and the quality evaluation process. Firms and customers can participate in each quality process. However, quality production is primarily the domain of firms; quality evaluation is primarily the domain of customers; and quality experience is the domain in which firms and customers interact. The framework offers several contributions.

First, our integrative quality framework identifies important underdeveloped connections among the three quality processes. For example, the idea of co-production has become widely accepted as an important aspect of managing customers (Bendapudi and Leone 2003; Meuter et al. 2000). We extend this literature by describing six connections between the quality production process and other quality processes that contribute to or result from co-production.

Second, our framework points to critical, yet overlooked, aspects of quality that can improve our understanding of it. As an example, while the study of emotion is important in consumer research, critics have argued that its impact on quality is underspecified (Bolton and SaxenaIyer 2009; Price, Arnould, and Tierney 1995). Our framework illuminates important roles for emotion as a filter that influences customers' perceptions and quality evaluations.

Third, our framework not only describes three quality processes but also identifies corresponding quality states residing within each process. These states are snapshots that provide researchers and managers the opportunity to measure and learn from quality as it is produced, experienced, and evaluated. We describe what generates these quality states and how they should be measured, which enhances decision makers' ability to manage these states.
Fourth, our framework generalizes across different types of firms (for-profit, nonprofit), offerings (products, services), and customers (businesses, individuals). We chose this approach because a general framework is necessary to provide a unifying view of quality, which is increasingly important in the face of rapid technological advances that constantly redefine organizations, markets, offerings, and their interactions.

We begin by describing broadly the three quality processes that constitute our framework. We then detail each process and its interconnections with the other processes. We close by highlighting the theoretical and managerial implications of our framework.

\section{An Integrative Quality Framework}

Our framework is comprised of three processes - the quality production process, the quality experience process, and the quality evaluation process. Two of these processes have been the subject of previous research. With a focus on the firm, the quality production process has been the domain of engineering, operations, and management research, while the quality evaluation process, with a focus on the customer, has been at the center of marketing and consumer research. We identify a critical third process that has been underresearched in marketing and other disciplines. This quality experience process contains a set of key intermediate activities in our integrative quality framework. Our framework identifies connections among all three processes. Figure 1 provides an overview of our framework. ${ }^{2}$ It describes each quality process, points to a quality state that occurs in each process, and identifies the key links between the quality processes. We define all terms used in this framework and throughout the article in Table 1. We italicize these terms when introducing their definitions into the text.

We define quality as a set of three distinct states of an offering's attributes' relative performance generated while producing, experiencing, and evaluating the offering. We do not combine these states into an overall concept of quality, because important insights and actionable recommendations follow from treating each state separately. Each state of quality is a comparative assessment of an offering's attribute's performance relative to a reference standard desired by either firms or customers. Here we build on a key idea in the gaps model of service quality (Parasuraman, Zeithaml, and Berry 1985) - namely, that quality is not simply an attribute's performance but rather an assessment of performance relative to a reference standard.

Each quality process relates to the other two processes through contemporaneous links (CL1, CL2, CL3) and dynamic links (DL1, DL2, DL3) shown in Figure 1 and

2To focus on our quality framework, Figure 1 omits antecedents and outcomes of the quality processes. Antecedents include the firm's and competitors' strategy and organizational structure (e.g., Barney 1991; Dalton et al. 1980; Porter 1998). Outcomes include purchase intent, trial, repeat purchase, product usage, firm costs, sales and share, profits, and stock returns (e.g., Anderson, Fornell, and Lehmann 1994; Anderson and Sullivan 1993; Bolton and Lemon 1999; Homburg, Koschate, and Hoyer 2005; Rust, Moorman, and Dickson 2002). 
FIGURE 1

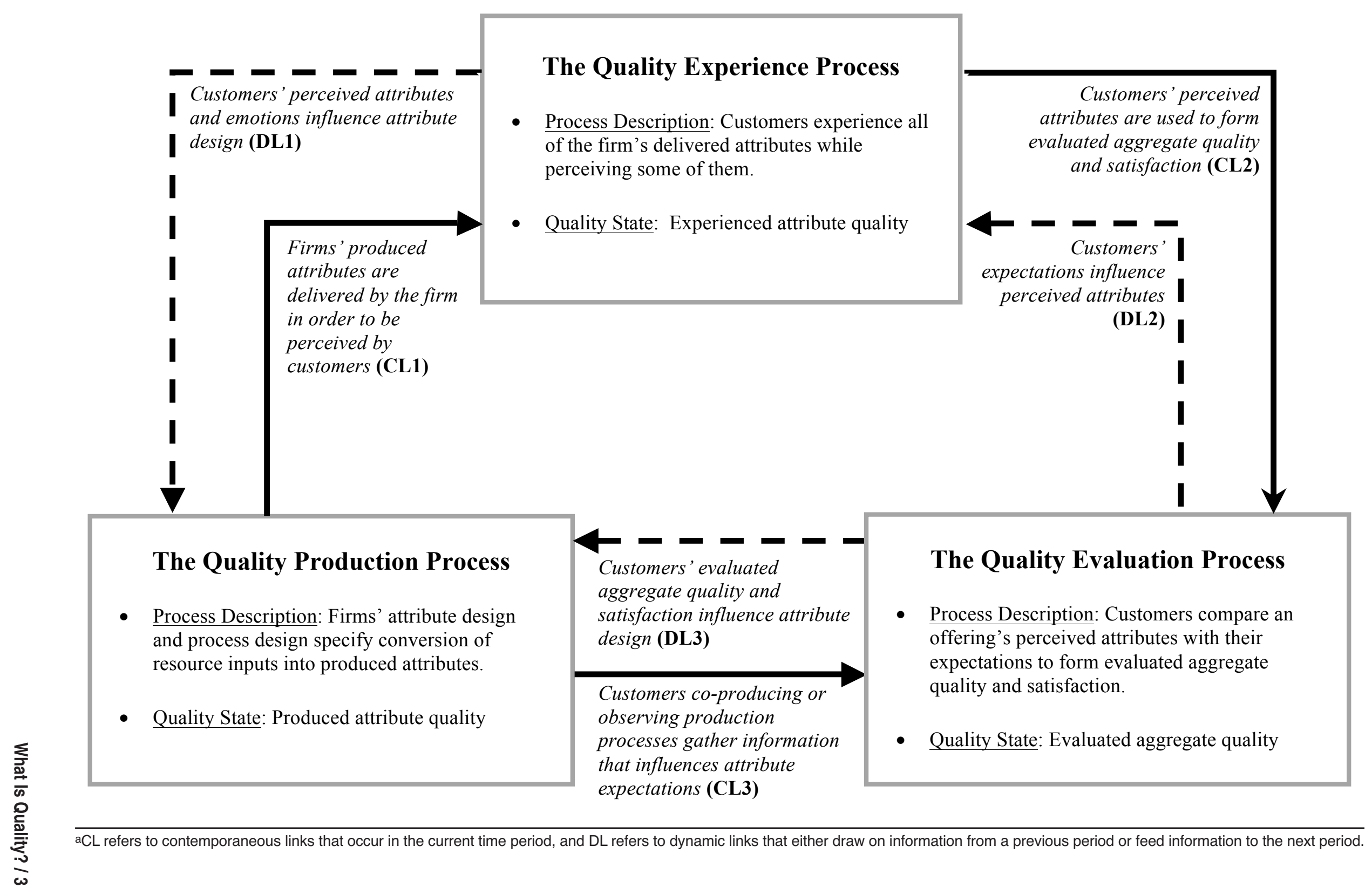




\section{Quality}

1. Quality is a set of three distinct states of an offering's attributes' relative performance generated while producing, experiencing, and evaluating the offering.

2. Offerings are products, services, or a combination of both.

3. Attributes are components, properties, or features that comprise an offering.

4. Attribute characteristics

- Performance is the extent or level of an attribute's functionality.

- Reliability is the probability of an attribute performing at its intended level of functionality.

\section{The Quality Production Process}

1. The quality production process occurs when firms use attribute design and process design specifications to convert their resource inputs and those from customers into produced attributes.

2. Within this process, the state of produced attribute quality is an offering's produced attribute performance relative to the firm's attribute design specification.

-Attribute design specifies the resource inputs (from firms, customers, or both), attribute performance, and attribute reliability that an offering must deliver.

- Process design implements the attribute design by specifying how resource inputs are converted into produced attributes.

3. Quality control methods consist of a set of procedures for monitoring produced attribute quality and maintaining or improving the process design specifications.

- Offline methods use experiments and simulations to improve produced attribute quality through changes in process design.

- Online methods monitor produced attribute quality and make necessary adjustments to the production process while it is in progress.

- Inspection methods measure resource inputs or produced attributes and reject those that do not meet specifications.

4. Resource inputs are the material and human resources used to generate produced attributes. Material resources include raw materials and intermediate offerings provided by the firm's suppliers. Human resources include physical labor, knowledge and insights provided by the firm's employees, suppliers, and, in cases of co-production, its customers.

The Quality Experience Process

1. The quality experience process occurs when firms (alone or with customers) deliver attributes for customers to experience and customers perceive these attributes through the lens of their measurement knowledge and motivation, emotions, and expectations.

2. Within this process, the state of experienced attribute quality is an offering's delivered attribute performance relative to a customer's 'ideal' expectation.

3. Attribute types

- Universal attributes are those for which customer preferences are homogeneous and measurement is unambiguous. - Preference attributes are those for which customer preferences are heterogeneous and measurement is unambiguous. - Idiosyncratic attributes are those for which customer preferences are heterogeneous and measurement is ambiguous.

4. Measurement knowledge is the customer's ability to assess attribute performance with minimal bias and variance relative to more objective measures.

5. Measurement motivation is the customer's desire to assess attribute performance with minimal bias and variance relative to more objective measures.

6. Emotion is the set of feelings evoked in customers during the quality experience process.

\section{The Quality Evaluation Process}

1. The quality evaluation process occurs when customers compare an offering's perceived attributes with their expectations to form summary judgments of quality and then satisfaction.

2. Within this process, the state of evaluated aggregate quality is the aggregation across attributes of an offering's perceived attribute performance relative to a customer's 'ideal' expectation.

3. Expectations are attribute performance reference levels a customer uses when perceiving and evaluating individual attributes.

- 'Will' expectations are the attribute performance levels a customer predicts or believes an offering is going to deliver.

- 'Ideal' expectations are the attribute performance levels that reflect a customer's ideal preferences across all offerings in a category.

- 'Should'expectations are the attribute performance levels a customer believes competing offerings in a category ought to deliver.

4. Expectation uncertainty is the variance in a customer's expectation of an attribute's performance. Each type of expectations has a corresponding uncertainty: 'will' uncertainty, 'ideal' uncertainty, and 'should' uncertainty.

5. Accumulated information consists of stored customer knowledge accrued from a customer's own experiences, other customers' experiences, firm strategies (e.g., customer relationship and brand strategies), media reports, and quality signals associated with each attribute.

6. Quality disconfirmation is the aggregation across attributes of an offering's perceived attribute performance relative to a customer's 'should' expectation.

7. Customer satisfaction is a postconsumption judgment that compares an offering's evaluated aggregate quality with its quality disconfirmation. 
described in subsequent sections. Contemporaneous links occur in the current time period, whereas dynamic links either draw on information from a previous period or feed information to the next period.

The quality production process occurs when firms use attribute design and process design specifications to convert their resource inputs and those from customers into produced attributes. Attribute design specifies the resource inputs (from firms, customers, or both), attribute performance, and attribute reliability that an offering must deliver. Process design implements the attribute design by specifying how resource inputs are converted into produced attributes. Within this process, the state of produced attribute quality is an offering's produced attribute performance relative to the firm's attribute design specification. The quality production process receives multiple sources of feedback, which firms can use to improve attribute design.

The quality experience process occurs when firms (alone or with customers) deliver attributes for customers to experience and customers perceive these attributes through the lens of their measurement knowledge and motivation, emotions, and expectations. ${ }^{3}$ In this process, there is translation from what the customer experiences (delivered attributes) to what the customer perceives. ${ }^{4}$ Customers will not perceive accurately all attributes they experience and will overlook some attributes entirely. Within this process, the state of experienced attribute quality is an offering's delivered attribute performance relative to a customer's 'ideal' expectation. Although customers and firms can both measure experienced attribute quality, we argue that firms are more able and motivated to do so.

The quality evaluation process occurs when customers compare an offering's perceived attributes with their expectations to form summary judgments of quality and then satisfaction. These expectations are determined by accumulated information consisting of stored customer knowledge accrued from a customer's own experiences, other customers' experiences, firm strategies (e.g., customer relationship and brand strategies), media reports, and quality signals associated with each attribute (Kirmani and Rao 2000; Woodruff, Cadotte, and Jenkins 1983). Within this process, the state of evaluated aggregate quality is the aggregation across attri butes of an offering's perceived attribute performance relative to a customer's 'ideal' expectation..$^{5}$ Although this state resides in customers, firms benefit from measuring it.

Our framework adopts a novel stance on the nature of quality. Specifically, quality occurs as three distinct and measurable states (produced attribute quality, experienced attribute quality, and evaluated aggregate quality). These

3Our conceptualization of a customer's role in the quality experience process is partially grounded on the classic learning models that distinguish between experience and evaluation (Dewey 1938; Kolb 1984).

${ }^{4}$ Hoch and Deighton $(1989$, p. 1) refer to this as a meeting of "objective truth" and subjective observation.

5Evaluated aggregate quality is similar to previous researchers' conceptualization of perceived quality (e.g., Zeithaml 1988). However, as we will show, our framework distinguishes between attribute perceptions and quality evaluations to expose more opportunities for theory development and managerial insight. quality states are generated within the three quality processes. Articulating and integrating the quality processes and corresponding quality states offers several important advantages for conceptualizing, measuring, and managing these processes and states. For example, by measuring experienced attribute quality, firms can better understand whether poor evaluated aggregate quality is due to delivered attributes or customer limitations in perceiving those attributes. This decomposition offers firms several strategies for dealing with poor evaluated aggregate quality beyond changing produced attributes. In Table 2, we describe the roles of firms and customers in the three quality processes and states. We elaborate on these roles in our discussion of each quality process.

The next three sections detail the three quality processes and associated quality states as depicted in Figure 2. We begin with the quality experience process because key ideas are introduced here that are important to the other processes. We then discuss the quality evaluation and quality production processes. Our framework's closed-loop, dynamic nature means that each quality process is an antecedent and a consequence of the other two processes.

\section{The Quality Experience Process}

The quality experience process occurs when attributes delivered by firms are perceived by customers. As shown in Figure 2, we differentiate between delivered attributes and perceived attributes because what is delivered to customers and what customers perceive is often not the same (Bolton and Drew 1991; Mitra and Golder 2006; Parasuraman, Zeithaml, and Berry 1985). The degree of correspondence between delivered and perceived attributes is determined by the nature of an attribute and customers' measurement knowledge and motivation, emotions, and 'will' expectations. Thus, an experience provides the opportunity for customers to perceive an attribute but does not necessarily mean they will perceive each attribute or perceive it accurately. Within the quality experience process, the state of experienced attribute quality is the performance of a delivered attribute relative to a customer's 'ideal' expectation of that attribute's performance. Therefore, experienced attribute quality will vary across customers depending on their 'ideal' expectations. Relative to a typical customer, firms are more capable of measuring attribute performance accurately because firms have greater access to measurement instruments. Firms also have the ability to measure customers' 'ideal' expectations and benefit by comparing those expectations with delivered attribute performance.

We offer four advances in the quality experience process: (1) experienced attribute quality as one state of quality, (2) a typology of an offering's attributes, (3) customer heterogeneity in measurement knowledge and measurement motivation, and (4) the impact of customer emotion.

\section{Experienced Attribute Quality}

Experienced attribute quality is the performance of a delivered attribute relative to a customer's 'ideal' expectation of that attribute. We define an attribute's performance as the extent or level of its functionality. Functionality varies 
TABLE 2

The Who, What, and Where of Quality Processes and Quality States

\begin{tabular}{|c|c|c|c|c|c|c|c|}
\hline Quality Process & Who Participates? & Quality State & $\begin{array}{l}\text { Level of } \\
\text { Aggregation for } \\
\text { Quality State }\end{array}$ & $\begin{array}{c}\text { Inputs to } \\
\text { Quality State } \\
\text { (Source of Input) }\end{array}$ & $\begin{array}{l}\text { Where } \\
\text { Quality } \\
\text { State } \\
\text { Resides? }\end{array}$ & $\begin{array}{l}\text { Who } \\
\text { Measures } \\
\text { Quality } \\
\text { State? }\end{array}$ & $\begin{array}{l}\text { Key Question Answered by } \\
\text { Measuring Quality Statea }\end{array}$ \\
\hline $\begin{array}{l}\text { Quality } \\
\text { production } \\
\text { process }\end{array}$ & $\begin{array}{l}\text { In a traditional setting, only } \\
\text { the firm participates. In a co- } \\
\text { production setting, the firm and } \\
\text { the customer both participate. }\end{array}$ & $\begin{array}{l}\text { Produced } \\
\text { attribute quality }\end{array}$ & Attribute level & $\begin{array}{l}\text {-Produced attribute } \\
\text { performance (firm) } \\
\text {-Attribute design } \\
\text { (firm) }\end{array}$ & Firm & Firm & $\begin{array}{l}\text { Whether to improve production } \\
\text { process through changes in } \\
\text { process design or quality control. }\end{array}$ \\
\hline $\begin{array}{l}\text { Quality } \\
\text { experience } \\
\text { process }\end{array}$ & $\begin{array}{l}\text { The firm delivers attributes } \\
\text { and the customer perceives } \\
\text { attributes. }\end{array}$ & $\begin{array}{l}\text { Experienced } \\
\text { attribute quality }\end{array}$ & Attribute level & $\begin{array}{l}\text {-Delivered attribute } \\
\text { performance (firm) } \\
\text {-'Ideal' expectations } \\
\text { (customer) }\end{array}$ & Customerb & Firmc & $\begin{array}{l}\text { Whether to shift delivered } \\
\text { attribute performance closer to } \\
\text { customer's 'ideal' expectation. }\end{array}$ \\
\hline $\begin{array}{l}\text { Quality } \\
\text { evaluation } \\
\text { process }\end{array}$ & $\begin{array}{l}\text { The customer evaluates } \\
\text { perceived attributes and } \\
\text { aggregates these evaluations. }\end{array}$ & $\begin{array}{l}\text { Evaluated } \\
\text { aggregate } \\
\text { quality }\end{array}$ & $\begin{array}{l}\text { Aggregation of } \\
\text { attributes }\end{array}$ & $\begin{array}{l}\text {-Perceived attribute } \\
\text { performance } \\
\text { (customer) } \\
\text { 'Ideal' expectations } \\
\text { (customer) }\end{array}$ & Customer & $\begin{array}{l}\text { Customer } \\
\text { and firm }\end{array}$ & $\begin{array}{l}\text { Whether to shift perceived } \\
\text { attribute performance closer to } \\
\text { customer's 'ideal' expectation. }\end{array}$ \\
\hline
\end{tabular}

aAdditional strategic options are included in Figure 3.

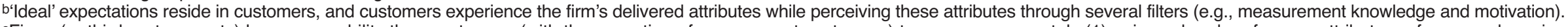

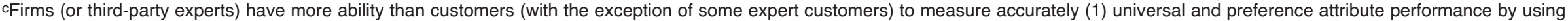

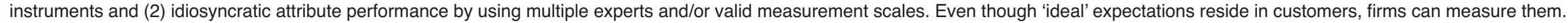


FIGURE 2

Details of Integrative Quality Frameworka

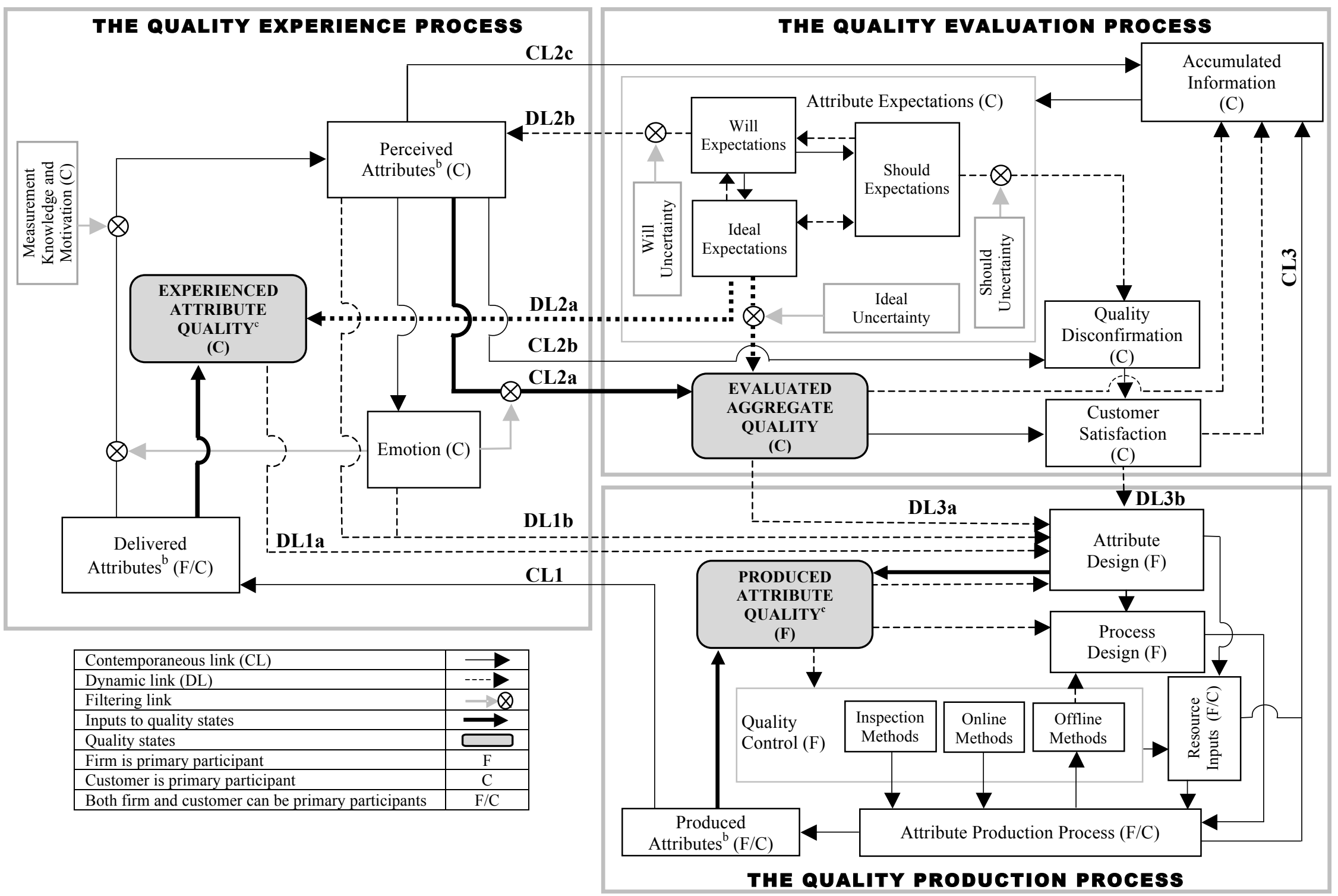

aFollowing Figure 1, only the links between the three quality processes are labeled CL or DL.

bThe three attribute types (universal, preference, and idiosyncratic) apply to produced attributes, delivered attributes, and perceived attributes.

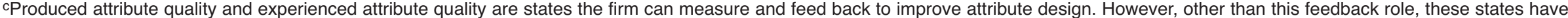
no process effects. In contrast, evaluated aggregate quality is both a state, which feeds back to attribute design, and a process input to customer satisfaction. 
across offerings. For example, automobile brakes differ in braking distance (in units of feet), which is a measure of a brake's performance, while restaurants differ in order fulfillment time (in units of seconds), which is a measure of responsiveness performance. Performance alone is not quality; quality assessments require comparison standards to convert attribute performance into quality states. For example, even if the braking distances of a sports car and a family sedan are identical, produced attribute quality will differ when the firm-specified braking distance for sports cars is shorter. An attribute's reliability is the probability of an attribute performing at its intended level of functionality. ${ }^{6}$ An attribute is unreliable when its performance falls outside the range of its design specification. For example, different automobiles with the same braking distance may fall outside their specified braking performance ranges with different frequencies.

Experienced attribute quality is important for firms to measure because it typically reflects a more accurate assessment of attribute performance than customers' perceived attributes (an input to evaluated aggregate quality). This is because perceived attributes are viewed through several customer filters that can prevent or bias their perception. Experienced attribute quality can be an elusive state to measure because it requires firms to accurately measure each attribute's performance and each customer's 'ideal' expectation. However, the firm's attribute performance design could bias its assessment of delivered attribute performance, and the firm's ideal attribute performance could bias its assessment of a customer's 'ideal' expectation. ${ }^{7}$ Given the potential for biased assessments, firms may want to supplement their own measures of experienced attribute quality with third-party assessments (e.g., a Consumer Reports rating relative to target segment preference). Furthermore, it is important to note that experienced attribute quality will vary as customers' 'ideal' expectations vary. Despite this, it is possible for firms to learn from experienced attribute quality. For example, customers have heterogeneous preferences for room temperature in a restaurant, so managers can use customers' average ideal temperature to maximize experienced attribute quality for temperature across customers.

\section{A Two-Dimensional Typology of Attributes}

We propose that the nature of an attribute will influence how accurately customers are able to perceive and evaluate its performance. To extend the literature, we offer a typology of attribute types based on two key dimensions. The first dimension, customer preference, describes whether customers have homogenous or heterogeneous attribute preferences. Derived from economic theory, this dimension

${ }^{6}$ For simplicity, our definitions of quality and quality states use "performance" to capture both the level of performance and the probability of performing at that level.

${ }^{7}$ Two confirmatory biases are possible. First, managers may see the firm's attribute performance design, not the actual level of delivered attribute performance. Second, managers may infer that customers have the same ideal attribute performance as the firm. These biases are more likely with attributes that cannot be measured with instruments or when customers are unfamiliar with instrument measures. differentiates between attributes with homogeneous preferences (e.g., a longer-lasting light bulb) and attributes with heterogeneous preferences (e.g., sweet vs. savory taste) (Desai 2001; Hotelling 1929; Salop 1979; Sutton 1986). Customer preferences are homogeneous for vector attributes, which are attributes for which all customers prefer either higher performance (e.g., airplane seat legroom) or lower performance (e.g., cabin noise). Customer preferences are heterogeneous for ideal-point attributes, which are attributes for which each customer has an individual ideal point (e.g., cabin temperature).

The second dimension, measurement ambiguity, refers to whether an attribute's performance can be measured unambiguously or ambiguously. Unambiguous attributes (e.g., seat width) can be measured with instruments such as measuring tapes, watches, odometers, thermometers, dynamometers, seismometers, measuring cups, scales, and so forth. Ambiguous attributes (e.g., aesthetics of an airline lounge) are measured through human senses (Kahn and Wansink 2004).

We combine our two dimensions of customer preference (homogeneous, heterogeneous) and measurement ambiguity (unambiguous, ambiguous) to derive the fourcelled typology of attributes depicted in Web Appendix A (http://www.marketingpower.com/jm_webappendix). We next describe each attribute type. ${ }^{8}$

Universal attributes are those for which customer preferences are homogeneous and measurement is unambiguous. For an airline, universal attributes include flight delay incidence, legroom, seat width, and cabin noise. Preference attributes are those for which customer preferences are heterogeneous and measurement is unambiguous. For an airline, preference attributes include arrival and departure times, meal cuisine type, cabin temperature, locations of exits and lavatories, and seating configuration and material (cloth or leather). Idiosyncratic attributes are those for which customer preferences are heterogeneous and measurement is ambiguous. Idiosyncratic attributes include elements of art, beauty, and social interaction. For an airline, idiosyncratic attributes include the aesthetics of an airline lounge, appearance of agents and flight attendants, and interactions with fellow passengers.

The fourth cell of the typology is empty because we could not uncover any attribute for which customers have homogeneous preferences and measurement is ambiguous. Some may argue that constructs like helpfulness belong in the fourth cell (i.e., it is measured with the senses and customers prefer more helpfulness). We contend that such constructs are a combination of individual attributes, and even when customers agree about the construct, they disagree about which attributes provide it. For example, helpfulness can be decomposed into universal attributes (e.g., wait time), preference attributes (e.g., time taken to explain), and idiosyncratic attributes (e.g., talkative demeanor). Therefore, any construct that fits into the empty fourth cell represents a higher-level construal that does not help us understand quality at the attribute level.

${ }^{8}$ We house our discussion of attribute types in the quality experience process. However, these types occur across all three quality processes. 


\section{Customer Measurement Knowledge and Motivation}

How accurately a customer translates delivered attributes into perceived attributes is influenced by both customer measurement knowledge and measurement motivation (see Figure 2). Measurement knowledge is the customer's ability to assess attribute performance with minimal bias and variance relative to more objective measures. The objective measure for universal and preference attributes is an instrument reading (e.g., thermometer, stopwatch), while an expert consensus (e.g., Delphi method, jury method) is used for idiosyncratic attributes. In general, higher measurement knowledge leads to a more direct translation from delivered attributes to perceived attributes. Prior literature suggests the important role of customers' measurement knowledge by describing attributes as "imperfectly observable" (Erdem and Keane 1996, p. 5). Measurement knowledge may be less important for universal attributes and preference attributes because they can be measured unambiguously and communicated to customers via third-party publications (e.g., Consumer Reports), firm strategies (e.g., advertising, packaging), and word of mouth (Tellis and Johnson 2007).

Measurement motivation is the customer's desire to assess attribute performance with minimal bias and variance relative to more objective measures (MacInnis, Moorman, and Jaworski 1991; Petty and Cacioppo 1986). High measurement motivation means that customers will devote resources to assess attribute performance. Like measurement knowledge, motivation may be less (more) important when attribute information is easier (more difficult) to assess. ${ }^{9}$

\section{Customer Emotion}

Customer emotion is a third intervening factor between delivered attributes and perceived attributes. Emotion is already in our framework as an idiosyncratic attribute (e.g., joy) delivered by a firm and perceived by customers (HennigThurau et al. 2006). However, emotion in Figure 2 refers to the set of feelings evoked in customers during the quality experience process (e.g., Arnould and Price 1993). These emotions are not attributes; they are an outcome of perceiving attributes and a filter in both subsequent attribute perceptions and evaluations. ${ }^{10}$ Emotion can be evoked by any attribute. Long waits can be frustrating and attentive care can be heartwarming.

Once customer emotions are generated, we predict three effects on the quality experience process. First, emotion may generate a confirmatory bias, which leads customers to perceive and to evaluate attributes that validate their feelings and to neglect disconfirming attributes (Cohen, Pham, and Andrade 2008). Second, negative emotion can make

${ }^{9}$ Measurement motivation can, over time, improve measurement knowledge. However, in our framework, we focus on their independent effects.

10 Our focus is on "integral" emotions, which are linked to the offering. However, emotions may also be "incidental" when they are not linked to the offering or when they are "anticipated" and stored as cognitions in accumulated information (Cohen, Pham, and Andrade 2008). customers' observations myopic, resulting in failure to perceive attributes delivered by the firm (Loewenstein 1996). Third, positive emotion can lead to holistic assessments wherein customers may underweight some attributes in forming quality evaluations. This can occur, for example, in white-water rafting when dirt and hard work are discounted while feelings of renewal and authenticity drive quality evaluations (Arnould and Price 1993). A final factor influencing the relationship between delivered attributes and perceived attributes is 'will' expectations, which are formed in the quality evaluation process. We discuss this in the next section.

\section{The Quality Evaluation Process}

Our depiction of the quality evaluation process in Figure 2 builds on an extensive literature (e.g., Anderson, Fornell, and Lehmann 1994; Bolton and Drew 1991; Bolton, Lemon, and Verhoef 2008; Price and Arnould 1999; Steenkamp 1990; Zeithaml 1988). The core feature of the quality evaluation process is the conversion of perceived attributes into an aggregated evaluation of quality, which is a summary judgment of the customer's experience of the firm's offering. This conversion is influenced by the customer's emotion during the quality experience and evaluation processes. Evaluated aggregate quality is formed by the customer because summary judgments are easier to store, retrieve, use, and share than individual attribute judgments. It is also more comprehensive and thus more suitable as an input to customer satisfaction.

Following the literature (Cronin and Taylor 1994; Parasuraman, Zeithaml, and Berry 1994), the quality evaluation process captures the formation of both transactional and global judgments. In the former case, perceived attributes from a transaction help determine evaluated aggregate quality and satisfaction for that specific consumption experience. These transaction-specific judgments are stored in memory as part of a customer's accumulated information. Over time, we expect customers to aggregate transactionspecific memories into global judgments of evaluated aggregate quality and satisfaction. Both transactional and global judgments may persist long after consumption has occurred. For example, customers will continue to hold judgments of evaluated aggregate quality and satisfaction for a car for years after owning it.

This section presents details about the quality evaluation process and makes four advances. First, we introduce the concept of evaluated aggregate quality, which allows us to bridge the focus on individual attributes (e.g., Cronin and Taylor 1992; Parasuraman, Zeithaml, and Berry 1988) with global judgments of evaluated quality and satisfaction (Anderson, Fornell, and Lehmann 1994; Tellis and Johnson 2007). Second, extending past research, we argue that emotion influences how perceived attributes form evaluated aggregate quality (see Figure 2). Third, we show distinct roles for three types of expectations. Fourth, we add a set of uncertainty filters that moderate the impact of each type of expectations on quality perceptions or judgments (see Rust et al. 1999). These filters are related to prior research on the zone of tolerance (e.g., Coyne 1989; Parasuraman, Berry, 
and Zeithaml 1991; Zeithaml, Berry, and Parasuraman 1993, 1996) because higher uncertainty is associated with higher tolerance of inferior attribute performance.

\section{Evaluated Aggregate Quality}

Evaluated aggregate quality is formed by aggregating comparisons of a customer's perceived attributes relative to the corresponding 'ideal' expectations for those attributes. The aggregation level is determined by two factors-customer expertise and attribute characteristics. First, experts' knowledge allows them to hold multiple judgments of evaluated aggregate quality, whereas novices may form one summary judgment. For example, experts may judge a wine's "appearance" on the basis of color and clarity attributes and its "balance" on the basis of attributes of sweetness, acidity, alcohol level, and tannin content. In contrast, novices might describe the same wine as being only sweet or dry. Second, two attribute characteristics influence the level of attribute aggregation. To begin, judgments of idiosyncratic attributes are more likely to be aggregated because these attributes cannot be measured precisely with instruments; universal and preference attributes can be measured precisely, and so they are more likely to remain disaggregated. For example, with airlines, a judgment of overall cabin comfort is easier to keep disaggregated into cabin noise and cabin temperature than a judgment of the flight attendants' overall social interaction, which includes difficult-to-measure attributes such as empathy and courtesy. In addition, some attributes may be aggregated because they group together naturally in the customer's mind. For example, customers may judge an airline's timeliness on the basis of departure time, arrival time, and baggage handling time.

Figure 2 offers two reasons why 'ideal' expectations provide the reference level for forming evaluated aggregate quality. First, 'ideal' expectations are customer-specific reference levels, which means that customers with different ideal points form different judgments of evaluated aggregate quality. Second, 'ideal' expectations enable evaluated aggregate quality to have ecological validity, meaning that it reflects the natural quality tiers customers hold for offerings. For example, while Motel 6 and Four Seasons both meet customers 'will' and 'should' expectations, customers do not judge these hotels as having the same evaluated aggregate quality. Instead, attributes are judged relative to each customer's 'ideal' expectations. Four Seasons' performance on multiple attributes leads to smaller gaps with 'ideal' expectations, resulting in a higher judgment of evaluated aggregate quality compared with Motel 6.

When combining perceptions of individual attributes into an aggregated judgment, customers are heterogeneous in the importance attached to each attribute. Importance weights are influenced by other factors in our framework (e.g., attribute type, 'ideal' uncertainty). Furthermore, our framework also allows customer emotion to influence evaluated aggregate quality. This effect may occur when the customer's processing resources are constrained (e.g., time pressure, cognitive load), the customer's motivation to process is low, or the customer lacks expertise in the target domain (Cohen, Pham, and Andrade 2008).
In addition to being a state of quality, evaluated aggregate quality is also an input to customer satisfaction. This dual role is different from the other two quality states. Produced attribute quality and experienced attribute quality are states, which can be measured by the firm and used to improve attribute design through feedback (see Figure 2). In contrast, evaluated aggregate quality is not only a state but also a key determinant of customer satisfaction. We now discuss customer expectations, which are also an important precursor of customer satisfaction.

\section{Customer Expectations}

Expectations are attribute performance reference levels a customer uses when perceiving and evaluating individual attributes. Individual attribute evaluations are aggregated to form evaluated aggregate quality and quality disconfirmation, which determine customer satisfaction (Churchill and Suprenant 1982; Kopalle and Lehmann 2001). Attribute expectations are adaptive to customer learning and change over time (Erdem and Keane 1996). This learning may be superficial or deep. Information can emanate from the customer's experiences or external sources such as third parties, competitors' offerings, and the firm itself. Firm information includes signals or cues correlated with an attribute's performance or reliability, such as price, advertising, market share, and reputation (Helloffs and Jacobson 1999; Kirmani and Rao 2000; Tellis and Wernerfelt 1987).

Customers use accumulated information to form three distinct but interrelated types of expectations about attribute performance - 'will,' 'ideal,' and 'should' expectations. Previous researchers have described these customer expectations but have not included all three in a single framework. Some research focuses on one expectation (e.g., 'will' in Oliver 1980; 'ideal' in Tse and Wilton 1988; 'should' in Cadotte, Woodruff, and Jenkins 1987) and others focus on two expectations (e.g., 'will' and 'should' in Boulding et al. 1993; 'will' and 'ideal' in Fornell et al. 1996). In addition, customers have confidence ranges for each expectation; therefore, our framework includes 'will' uncertainty, 'ideal' uncertainty, and 'should' uncertainty. Following Rust et al. (1999), we view expectation uncertainty as the variance in a customer's expectation of an attribute's performance.

'Will' expectations. A customer's 'will' expectations are the attribute performance levels a customer predicts or believes an offering is going to deliver (Boulding et al. 1993; Zeithaml, Berry, and Parasuraman 1993). 'Will' expectations are the result of a customer's prior experience with the offering and/or prior beliefs based on any of the information sources noted above. These expectations have been shown to "influence [customers'] perceptions of the data" (Boulding, Kalra, and Staelin 1999, p. 463; Hoch and Deighton 1989). We refer to these perceptions as "perceived attributes" in Figure 2. 'Will' expectations shape perceived attributes in three key ways. First, 'will' expectations shift customers' observations toward their expectations as part of a confirmatory bias (Boulding, Kalra, and Staelin 1999). Second, when measurement knowledge or motivation is low, customers retrieve 'will' expectations instead of 
directly observing delivered attributes. Third, when 'will' uncertainty is high because of exposure to divergent attribute performance levels, customers emphasize perceived attributes instead of their stored expectations to resolve their uncertainty (Rust et al. 1999).

'Ideal' expectations. 'Ideal' expectations are the attribute performance levels that reflect a customer's ideal preferences across all offerings in a category. Perceived attributes are assessed relative to a customer's 'ideal' expectations in forming a judgment of evaluated aggregate quality (see Figure 2; Tse and Wilton 1988; Zeithaml, Berry, and Parasuraman 1993). For universal attributes, customers' 'ideal' expectations are identical because customer preferences are homogeneous. However, for preference and idiosyncratic attributes, customers have different 'ideal' expectations. 'Ideal' uncertainty will be zero (or close to zero) for universal attributes because all customers share a common preference and higher for preference and idiosyncratic attributes because preferences are heterogeneous. When customers have high 'ideal' uncertainty for an attribute, the influence of 'ideal' expectations for that particular attribute on evaluated aggregate quality is lower than when customers have more certain preferences.

'Should' expectations. 'Should' expectations are the attribute performance levels a customer believes competing offerings in a category ought to deliver (Boulding, Kalra, and Staelin 1999; Boulding et al. 1993; Cadotte, Woodruff, and Jenkins 1987; Tse and Wilton 1988). 'Should' expectations are based on a normative expectation related to the concepts of perceived equity and fairness, in which an offering is assessed relative to the price paid, the offering purchased by other customers, or competitive offerings available in the market (Bolton and Lemon 1999; Boulding et al. 1993; Oliver and Swan 1989). ${ }^{11}$ As a result, while 'ideal' expectations are the same for all offerings in a category (e.g., hotels), 'should' expectations are the same for a narrower set of competing offerings within the category (e.g., 5-star hotels). 'Should' expectations are the reference levels against which perceived attributes are compared in determining quality disconfirmation (Figure 2; Kumar, Kalwani, and Dada 1997; Oliver 2009).

For universal attributes, we view a 'should' expectation as the lower bound establishing the performance level that ought to be provided by competing offerings in the category. For example, customers believe an airline 'should' provide legroom of 15 inches, while their 'ideal' expectation for legroom is typically greater than that level. For preference and idiosyncratic attributes, customer preference diminishes as performance deviates from the ideal point (e.g., cabin temperature). Therefore, a 'should' expectation contains both a lower bound and an upper bound, with the attribute's 'ideal' expectation falling in between. For example, a customer with an 'ideal' cabin temperature expectation of $72^{\circ} \mathrm{F}$ may believe an airline 'should' provide a cabin temperature of at least $70^{\circ} \mathrm{F}$ and at most $75^{\circ} \mathrm{F}$. Finally,

\footnotetext{
${ }^{11}$ These concepts are similar to the concept of value in the American Customer Satisfaction Index (i.e., quality given price and price given quality) (Fornell et al. 1996).
}

'should' uncertainty is a filter for 'should' expectations. When 'should' uncertainty is high, as with novices or when service quality is highly variable, customers will weight those attributes less in their aggregation of quality disconfirmation (see Figure 2).

Relationships among three types of expectations. Following Oliver (2009), we view the three types of expectations as distinct but related to one another (see Figure 2). We conceptualize 'will' expectations as the most elemental expectation because 'will' expectations are formed at the attribute level and are distinct for each offering. 'Ideal' expectations are also formed at the attribute level but are the same for all offerings in a category. This is logical to ensure that customers' judgments of evaluated aggregate quality are in sync with their perceived attribute performance. 'Ideal' expectations may change when customers learn about new products and update their 'will' expectations. Moreover, 'should' expectations are distinct from 'ideal' expectations because 'should' expectations are influenced, in part, by a customer's 'will' expectations for offerings in the competitive set, whereas 'ideal' expectations are based on a customer's most preferred attribute performance levels in the broader category. Furthermore, 'should' expectations are distinct from a specific offering's 'will' expectations because 'should' expectations cut across the competitive set of offerings within a category, whereas 'will' expectations are specific to a particular offering.

\section{Quality Disconfirmation}

Quality disconfirmation is the aggregation across attributes of an offering's perceived attribute performance relative to a customer's 'should' expectation. For universal attributes, quality disconfirmation is positive when perceived attribute performance exceeds a 'should' expectation and negative when perceived attribute performance falls below a 'should' expectation. For example, if the 'should' expectation for legroom is 15 inches, legroom above (below) 15 inches will result in positive (negative) quality disconfirmation, while 15 inches will have no quality disconfirmation. For preference and idiosyncratic attributes, quality disconfirmation is positive when perceived attribute performance is within the lower and upper bounds of a 'should' expectation. Returning to our cabin temperature example, positive (negative) quality disconfirmation occurs for temperatures above (below) $70^{\circ} \mathrm{F}$ and below (above) $75^{\circ} \mathrm{F}$ and no quality disconfirmation occurs for temperatures of $70^{\circ} \mathrm{F}$ or $75^{\circ} \mathrm{F}$.

We use 'should' expectations as the reference level for determining quality disconfirmation because 'should' expectations capture additional norms such as perceived equity and fairness. These norms are important to customer satisfaction and extend beyond the product-based norms in 'will' and 'ideal' expectations. Moreover, 'should' expectations enhance the impact of quality disconfirmation on customer satisfaction because an offering's attribute's performance is more likely to deviate from 'should' expectations of competing offerings in a category than from an offeringspecific 'will' expectation. 


\section{Customer Satisfaction}

Customer satisfaction is a postconsumption judgment that compares an offering's evaluated aggregate quality with its quality disconfirmation. ${ }^{12}$ Thus, customer satisfaction is a comparison between quality (i.e., evaluated aggregate quality) and a quality standard (i.e., quality disconfirmation), whereas each quality state is a comparison of attribute performance with a performance standard (i.e., attribute design or 'ideal' expectations). A customer's aggregation level for quality disconfirmation will match the aggregation level for evaluated aggregate quality, so these two concepts can be compared easily in forming customer satisfaction. However, attribute importance weights used in these aggregations do not need to be the same (Oliver 2009).

Positive quality disconfirmation increases satisfaction; negative quality disconfirmation decreases satisfaction. When perceived attributes equal 'should' expectations, there is "no change in customer satisfaction beyond the effect of the [evaluated aggregate] quality level that already exists" (Oliver 1996, p. 112).

Across offerings, different judgments of evaluated aggregate quality can lead to the same level of satisfaction when 'should' expectations are different. Returning to the example of Motel 6 and Four Seasons, 'should' expectations are more stringent for Four Seasons because it is in the competitive set of 5-star hotels (Woodruff, Cadotte, and Jenkins 1983). As a result, a customer's judgment of evaluated aggregate quality must be higher for Four Seasons to result in the same satisfaction level as Motel 6. A similar point is made by previous researchers who suggest "that customer satisfaction is dependent on ... the ratio of benefits received relative to costs incurred" (Anderson, Fornell, and Lehmann 1994, p. 55; see also Zeithaml 1988).

We now move to the quality production process in which firms strive to produce attributes, sometimes with customer co-production, that conform to the attribute design specifications set by the firm based on input from customers.

\section{The Quality Production Process}

The quality production process is primarily the domain of researchers and managers in operations and engineering who establish standards for and then generate goods and services (e.g., Feigenbaum 1991; Montgomery 2008). This literature tends to focus on specifications for attributes that can be measured easily and for which customers have homogeneous preferences (i.e., universal attributes). For example, Shewhart (1986, p. 1, italics added) defines specifications as a "statistical state constituting a limit ... in improving the uniformity of quality." Thus, giving more attention to preference and idiosyncratic attributes as well as production processes

12Oliver $(2009$, p. 8) offers a more conceptual definition of satisfaction as "the consumer's fulfillment response. It is a judgment that a product/service feature, or the product or service itself, provided (or is providing) a pleasurable level of consumption-related fulfillment, including levels of under- or overfulfillment." Consistent with our approach in this article, our definition of satisfaction is more operational in nature. for services will offer deeper insights. In this section, we begin by conceptualizing the subprocesses within quality production. We then focus on how these subprocesses link to our broader conceptualization of quality, including the role of co-production.

\section{Key Subprocesses in Quality Production}

Figure 2 indicates that producing an offering is a function of attribute design, process design, resource inputs, and various methods of controlling the production process. Attribute design levels are established by the firm, ideally based on input from customers (Green and Srinivasan 1990; Griffin and Hauser 1993; Hauser and Clausing 1988). In our framework, customer input to attribute design comes from customers' prior perceptions of attributes, their resulting emotion, the three quality states, and customer satisfaction.

Once attribute design (i.e., resource inputs and attribute performance) has been specified, process design and quality control are the remaining inputs to the attribute production process (Hamada, Mackay, and Whitney 1993; Woodall and Montgomery 1999). Process design specifies the production process that will produce the attribute design specifications. Firms rely on a set of quality control methods-offline, online, and inspection - for monitoring produced attribute quality and maintaining or improving the process design specifications. ${ }^{13}$

The success of the attribute production process can be assessed by the resulting state of produced attribute quality. Produced attributes will be the same as delivered attributes when offerings are produced and consumed simultaneously (e.g., many services) or when offerings do not change over time and distance (e.g., many durable goods). In other cases, produced attributes may change between production and consumption (e.g., food loses freshness or metal rusts). Therefore, we use delivered attributes to distinguish attributes the customer experiences from attributes the firm produces.

Three quality control methods can be used to improve produced attribute quality. Offline methods use experiments and simulations to improve produced attribute quality through changes in process design (e.g., Kackar 1985). Offline methods can be used in services by training employees, installing superior equipment, and increasing process efficiency. Online methods monitor produced attribute quality and make necessary adjustments to the production process while it is in progress (e.g., Gong, Jwo, and Tang 1997). For customized services, like medical services, online process controls can be implemented by training providers to monitor and modify service delivery as it occurs. Inspection methods measure resource inputs (e.g., Ding, Greenberg, and Matsuo 1998) or produced attributes (e.g., Mayer, Nickerson, and Owan 2004) and reject those that do not meet specifications. These methods do not apply to services that are produced and consumed simultaneously. However, they could apply when there is a delay between production and consumption (e.g., auto repairs, tax preparation).

13The terms "offline" and "online" are used in the operations literature in the production line context and do not refer to the Internet. Although these methods were developed primarily for goods, they can also be applied to services. 
Each quality control method may be more or less useful for producing certain types of attributes. For example, offline methods are especially relevant for universal attributes because attribute performance does not need to be customized to individual preferences. In contrast, online methods take on greater prominence with preference and idiosyncratic attributes because firms need to match attribute performance with heterogeneous customer preferences. Inspection methods could be employed with all types of attributes.

\section{Co-Production of an Offering's Attributes}

Standard notions of the quality production process tend to separate it from the quality experience and quality evaluation processes. In this view, an offering's attributes are produced by firms and then delivered to customers whose postconsumption feedback is used to update attribute design. However, customers sometimes observe production processes (e.g., many services are produced and consumed simultaneously) and store these observations (see the "Accumulated Information" box in Figure 2). More important, customers can play a role with firms in the production of many goods and services (Bitner et al. 1997; Kelley, Donnelly, and Skinner 1990). Our framework examines coproduction in six ways.

First, when customers contribute to produced attributes (e.g., bagging groceries or providing goals to a financial planner), delivered attributes are more likely to approximate what customers want. Second, involvement in co-production should increase customer measurement knowledge and motivation. When this happens, customers will place more emphasis on perceived attributes and less emphasis on 'will' expectations because they are more likely to perceive accurately the attributes firms deliver. Third, co-production enables firms to monitor customers' emotions, which allows managers to adjust produced attributes in real time (Menon and Dubé 2007). ${ }^{14}$ This may involve changing the level of an existing attribute (e.g., faster service) or adding new attributes (e.g., free wine with dinner) to accommodate a customer.

Fourth, when customers provide resource inputs or participate in the production process, the resulting accumulated information has a positive impact on 'will' expectations (Bettencourt 1997; Kelley, Donnelly, and Skinner 1990), which improves attribute perceptions. Fifth, co-production may shift 'ideal' expectations toward what customers perceive. Finally, co-production reduces 'will' uncertainty because customers have more knowledge of a co-produced attribute's performance. This increases the influence of 'will' expectations.

These positive impacts of co-production provide insights into why evaluated aggregate quality often increases through co-production (Bettencourt 1997; Kelley, Donnelly, and Skinner 1990; Lengnick-Hall 1996). Unfor-

\footnotetext{
${ }^{14}$ Arnould and Price (1993) describe how companies such as Disney and McDonald's train employees to display enthusiasm or humor to improve the customer experience. Other research shows how employees' emotions have a positive effect on customers' emotions (Hennig-Thurau et al. 2006).
}

tunately, firms may not benefit when customers believe this increase is due to their own efforts (Bendapudi and Leone 2003). However, when service quality is poor, customers may also accept some of the blame (Bitner et al. 1997).

\section{Implications for Theory}

Our framework offers two sets of theoretical implications: (1) integrating three quality processes into a single framework and (2) broadening the range of concepts included in that framework. Empirical research is necessary to establish the validity of these ideas. To facilitate, Table 3 offers 21 testable propositions derived from our integrative framework.

\section{Integrating the Quality Processes}

Opportunities for knowledge transfer across disciplines. By identifying and defining the three quality processes, the three quality states, and their points of interconnection, researchers should see more opportunities for crossfertilization. To facilitate this, Web Appendix B (see http:// www.marketingpower.com/jm_webappendix) organizes the 252 quality articles published in Journal of Marketing and Management Science from 1988 to 2010 according to Figure 1.15 This Appendix reveals that Journal of Marketing has many articles on the quality evaluation process and only two on the quality production process. Conversely, Management Science has many articles on the quality production process and only one on the quality evaluation process.

Our framework also enhances knowledge transfer by providing definitions that apply to both goods and services (see Table 1) and recommendations for measure development in future research. The Appendix provides operational definitions of our key concepts, illustrative measures, and advice for researchers tackling this challenge. Finally, our integrative quality framework may be useful outside of product consumption experiences. Like Oliver (2009), who identifies opportunities to study satisfaction across domains as diverse as job satisfaction, family satisfaction, and life satisfaction, we believe that our quality framework is useful in other areas as well. While some terms may need to be operationalized for different contexts, the generic quality processes and states are likely to transfer to other fields. Future empirical research should determine the boundaries of this applicability.

Identification of underexplored research areas. Our framework highlights four areas not addressed sufficiently in the literature. First, as we noted above, the quality production process has not received much attention in Journal of Marketing because this process traditionally has been viewed as not involving customers. Our framework expands on recent research to describe six ways co-production plays a role in all three quality processes. Second, the quality evaluation process has not received much attention among operations or engineering scholars in Management Science because the path from produced attributes to evaluated aggregate quality has not been elucidated previously. Our

\footnotetext{
${ }^{15}$ Articles on quality topics outside the bounds of Figure 1 (e.g., the impact of quality on firm financial performance) are grouped into several additional links in Web Appendix B.
} 
The Quality Production Process

1. As co-produced attribute performance increases, 'will' expectations increase.

2. As co-production increases, 'will' uncertainty, 'ideal' uncertainty, and 'should' uncertainty decrease.

3. As co-production increases, 'ideal' expectations shift toward the attribute performance produced by a customer.

4. As co-production increases, measurement knowledge and motivation increase.

5. As co-production increases, experienced attribute quality increases because a customer produces attributes closer to his or her 'ideal' expectations.

6. Firms that measure and feed back experienced attribute quality and evaluated aggregate quality are more likely to match their offering's attribute design with customers' 'ideal' expectations over time.

7. Firms that measure and feed back produced attribute quality are more likely to improve their offering's process design over time.

The Quality Experience Process

1. The gap between delivered attribute performance and perceived attribute performance decreases as customer measurement knowledge and motivation increase.

2. The gap between delivered attribute performance and perceived attribute performance changes as customer emotion changes. a

3. The gap between delivered attribute performance and perceived attribute performance increases as 'will' expectation increases.

4. The gap between delivered attribute performance and perceived attribute performance is smaller for universal attributes than for preference attributes and idiosyncratic attributes.

5. Higher 'will' uncertainty for an attribute increases customer attention in perceiving that attribute.

6. Service providers who monitor customer emotions during their service delivery are more likely to adapt their service's attributes and improve experienced attribute quality.

7. Firms that measure and feed back experienced attribute quality to attribute design have higher evaluated aggregate quality and satisfaction.

\section{The Quality Evaluation Process}

1. Emotions influence the effect of perceived attributes on evaluated aggregate quality.

2. Emotions influence the relative importance of attributes in forming evaluated aggregate quality.

3. Higher 'ideal' uncertainty for an attribute decreases the relative importance of that attribute in evaluated aggregate quality.

4. Higher 'should' uncertainty for an attribute decreases the relative importance of that attribute in quality disconfirmation.

5. As customer expertise increases, the extent of attribute aggregation in evaluated aggregate quality and satisfaction decreases.

6. Higher satisfaction increases 'will,' 'ideal,' and 'should' expectations.

7. Firms that measure and feed back evaluated aggregate quality to attribute design have higher satisfaction.

aAcross all propositions involving emotion, attributes associated with some emotions (e.g., joy) may result in positive influence while attributes associated with other emotions (e.g., anger) may result in negative influence. The effects of other emotions (e.g., love) are less clear. Finally, the effects of any emotion may vary with contextual factors.

framework offers a set of factors influencing this path (see Figure 2).

Third, across the two journals, few papers study the quality experience process. Consistent with Parasuraman, Zeithaml, and Berry (1985), our framework shows that a firm's produced attributes do not directly determine customers' evaluated aggregate quality. We contribute to this literature by identifying intervening customer factors that influence this process, including emotion, measurement knowledge, and measurement motivation. Fourth, there is a need to clarify the relationships among the three types of expectations. We propose that 'will' expectations are the most elemental form and that 'ideal' and 'should' expectations relate to them. In contrast, others have modeled 'will' and 'should' expectations as independent (Boulding et al. 1993) or measured customer satisfaction without explicitly mentioning 'should' expectations as a comparison standard (e.g., the American Customer Satisfaction Index; see Fornell et al. 1996). ${ }^{16}$ Empirical work should consider more

16The American Customer Satisfaction Index uses perceived value (i.e., price given quality and quality given price), a concept related to quality disconfirmation (which is partially determined by 'should' expectations), as a determinant of satisfaction. deeply the process by which expectations are formed, stored, and retrieved.

\section{Broadening Quality Concepts}

Our framework illuminates new concepts that broaden previous quality frameworks. We highlight two here-the role of customer filters and the impact of attribute types.

Role of customer filters. One of the persistent challenges in defining quality is that customers can disagree about the evaluated aggregate quality of the same delivered attributes. Our framework's three critical customer filters help account for these differences. The measurement knowledge and motivation filter can result in different perceptions of delivered attributes. The emotion filter offers insight into situations when emotions interact with, or possibly even override, perceptions and evaluations (e.g., impulse purchases). The expectations uncertainty filters moderate each of the three corresponding expectations. As expectations uncertainty decreases, the impact of expectations increases. In the case of a 'will' uncertainty decrease, customers place greater weight on 'will' expectations and, at the extreme, substitute 'will' expectations for perceived attributes, particularly those for which they have less mea- 
surement knowledge or motivation. With 'ideal' and 'should' expectations, lower uncertainty increases the weight placed on those attributes when forming evaluated aggregate quality or quality disconfirmation.

Impact of attribute types. We offer a typology of attri butes, which complements previous studies that conceptualize attributes in more focused contexts (Brady and Cronin 2001; Brucks, Zeithaml, and Naylor 2000; Garvin 1984; Parasuraman, Zeithaml, and Berry 1985). Table 4 shows how attributes conceptualized in these studies map into our typology.

Our typology also complements the search-experiencecredence typology 17 in two ways. First, instead of focusing only on attribute characteristics, we argue that heterogeneity in customer measurement knowledge or measurement motivation also influences customer learning about an attribute (Hoch and Deighton 1989). Given this, the same attribute could be a search attribute for some customers and an experience attribute for others. Second, today's informationrich environment allows customers to view more attributes as search attributes based on other customers' experiences. For example, easy access to websites, discussion boards, and ratings agencies inform customers about offerings traditionally viewed as experience or credence goods (Huang, Lurie, and Mitra 2009). Our typology avoids this confusion by offering mutually exclusive attribute types that are independent of customers' measurement knowledge, measurement motivation, and familiarity with other customers' experiences.

\section{Implications for Practice}

Mirroring our theoretical implications, we now present managerial implications derived from (1) integrating the three quality processes and (2) broadening the concepts in our quality framework. The value of these implications awaits confirmation through empirical testing.

\section{Integrating the Quality Processes}

We highlight two contributions here-strategies firms can use to improve customer satisfaction and customer feedback mechanisms firms can use to improve quality states.

Improving customer satisfaction. Given the quality evaluation process concludes with customer satisfaction, we can examine factors across all three quality processes that contribute to customer satisfaction. Figure 3 describes 20 strategies derived from our framework. Of these strategies, 11 affect both key levers for improving customer satisfaction (i.e., increasing quality disconfirmation and increasing evaluated aggregate quality), and nine affect one lever.

Surprisingly, of the 17 strategies for improving evaluated aggregate quality, only four involve actual changes in

${ }^{17}$ Based on the work of Nelson (1970) and Darby and Karni (1973), Tirole $(1988$, p. 95, 106) defines search attributes as those whose "quality ... can be ascertained by consumers before a purchase," experience attributes as those "whose characteristics are learned by consumers only after purchase," and credence attributes as those whose "aspects of the quality ... is [sic] rarely learned, even after consumption." produced attributes. This offers insight into why improving produced attributes may have little effect on satisfaction (Kordupleski, Rust, and Zahorik 1993; Rust, Zahorik, and Keiningham 1995). Firms may realize better returns by improving customers' measurement knowledge and motivation, shaping customers' expectations, adjusting customers' expectations uncertainty, or influencing customers' emotions. For example, our framework suggests two mechanisms that explain why Southwest Airlines' use of humor can increase customer satisfaction. Activating a positive emotional filter may lead customers to overweight favorable attributes and ignore unfavorable attributes in forming evaluated aggregate quality. Positive emotions may also result in a higher level of social interaction co-produced by passengers and flight attendants.

Our framework points to multiple paths that can be influenced by strategies targeting expectations. Improving 'will' expectations enhances perceived attribute performance. These enhanced perceptions have a positive effect on both evaluated aggregate quality and satisfaction (acting through quality disconfirmation). However, increasing 'will' expectations may also increase 'ideal' expectations, which decreases evaluated aggregate quality, or increase 'should' expectations, which decreases quality disconfirmation and satisfaction. Managers must understand the relative impacts of these three effects before targeting expectations.

The appropriateness of the strategies in Figure 3 is contingent not only on their costs but also on an offering's attribute performance relative to competitors. Firms with a competitive advantage should consider strategies 2, 6, 9, 12, and 17. Firms with a disadvantage should consider strategies $3,7,8,13$, and 16 . Once verified in empirical testing, these ideas should help managers use quality strategies more effectively to improve firm performance (Morgan and Vorhies 2001; Zeithaml, Berry, and Parasuraman 1988).

Managing customer feedback. Our framework offers a range of ways that companies can learn from customers to improve quality states. We build on the extant literature that has viewed this feedback as occurring when customer inputs are used to determine attribute design in the initial stages of product development (e.g., Green and Srinivasan 1990; Griffin and Hauser 1993; Hauser and Clausing 1988). We uncover six additional types of feedback across the three quality processes that can drive attribute design (see Figure 2). These sources of feedback emanate from produced attribute quality, experienced attribute quality, perceived attributes, emotion, evaluated aggregate quality, and customer satisfaction. Given this, our framework alerts managers to the wider range of learning opportunities and possible metrics in the quality processes.

\section{Broadening Quality Concepts}

We highlight two advances for practice from broadening the concepts included in our quality framework-managing customer emotions and managing trade-offs in attribute selection.

Managing customer emotions. Our framework indicates that some emotions can heighten the more cognitive, rational processes of quality experience and quality evaluation. 
TABLE 4

How the Integrative Quality Framework Relates to Existing Quality Frameworks

\begin{tabular}{|c|c|c|c|c|}
\hline \multirow[b]{3}{*}{$\begin{array}{l}\text { Elements of the Integrative } \\
\text { Quality Framework }\end{array}$} & \multicolumn{4}{|c|}{ Quality Dimensions in Existing Frameworksa } \\
\hline & \multicolumn{2}{|c|}{ Products } & \multicolumn{2}{|c|}{ Services } \\
\hline & Garvin (1984) & $\begin{array}{l}\text { Brucks, Zeithaml, } \\
\text { and Naylor (2000) }\end{array}$ & $\begin{array}{l}\text { Parasuraman, } \\
\text { Zeithaml, and } \\
\text { Berry (1985) }\end{array}$ & $\begin{array}{c}\text { Brady and Cronin } \\
(2001)\end{array}$ \\
\hline The Quality Production Process & Conformance & & $\begin{array}{c}\text { Competence, } \\
\text { credibility, } \\
\text { understanding the } \\
\text { customer }\end{array}$ & Expertise, valencec \\
\hline
\end{tabular}

The Quality Experience Process

Attribute Types ${ }^{b}$

Universal

Durability,
serviceability

Preference

Idiosyncratic

Attribute Characteristics

Performance

Reliability

The Quality Evaluation Process
Aesthetics

Features

Performance

Reliability

Perceived quality

\begin{abstract}
Durability, ease of use, ${ }^{d}$ serviceability

Versatility$$
\text { y }
$$

Responsiveness,

Tangibles

Communication, courtesy

Performance

Prestige
Waiting time

Behavior, ambient conditions, design, tangibles

Attitude, social factors ${ }^{c}$

aWe categorize each quality dimension from the four existing frameworks with the element of our framework that has the most overlap with that dimension's definition, description, and/or examples as discussed in each article. Showing that our framework accommodates both product and service views of quality does not diminish the product- or service-specific insights generated by these four frameworks.

bWe differentiate between attribute types and attribute characteristics because we view all attribute types as having the characteristics of performance and reliability.

cThese two dimensions are about customers whereas the other dimensions in Brady and Cronin (2001) are about the service or service providers.

dSome quality dimensions (e.g., ease of use) describe a benefit with universal appeal, but we advise identifying the specific attribute or attributes that generate this benefit. These attributes can then be categorized into universal, preference, or idiosyncratic attribute types.

Other emotions may shut down these processes. As a result, some firms may prefer that emotions, rather than an offering's attributes, dominate their customers' experiences (e.g., Coca-Cola emphasizes happiness/refreshment over sweet taste, and Disneyland emphasizes joy over g-force). In other cases, firms may help a customer transition from a negative emotion to a positive emotion. For example, when a customer becomes angry over poor service delivery, the firm may want to diminish this anger before addressing deficiencies in attribute performance. Here, an improvement in emotion could be initiated by a free gift, even one unrelated to the service (e.g., candy, pen).

Managing trade-offs in attribute selection. Three tradeoffs must be managed when selecting from among our proposed attribute types. First, customers will observe improvements in universal attributes more quickly because these improvements are easier to communicate (measurement is unambiguous) and all customers value these attributes similarly (preferences are homogeneous). However, these two characteristics also make it easier for competitors to imitate strategies based on universal attribute improvements. In contrast, customers will observe changes in idiosyncratic attri- butes more slowly because measurement is ambiguous and preferences are heterogeneous. As a result, firms may find it easier to differentiate when improving idiosyncratic attributes.

Second, firms offering goods or services comprised primarily of universal attributes will tend to have shorter product lines and fewer customer segments because customer preferences are homogeneous for these attributes. When preference attributes become more prominent, markets should be divided into narrower segments. Third, when firms' produced attributes are superior, firms should help customers increase their measurement knowledge and motivation so they can perceive attribute advantages. In cases in which it is too costly to increase customers' measurement knowledge and motivation, firms can promote experts' assessments.

\section{Conclusion}

Quality is a multifaceted concept in management practice and scholarly research. It has been approached from a variety of perspectives over many decades. We integrate the vast quality literature to offer a unified framework of quality to researchers and managers from different disciplines. The primary contributions of the framework are as follows: 
FIGURE 3

Strategies to Improve Customer Satisfactiona

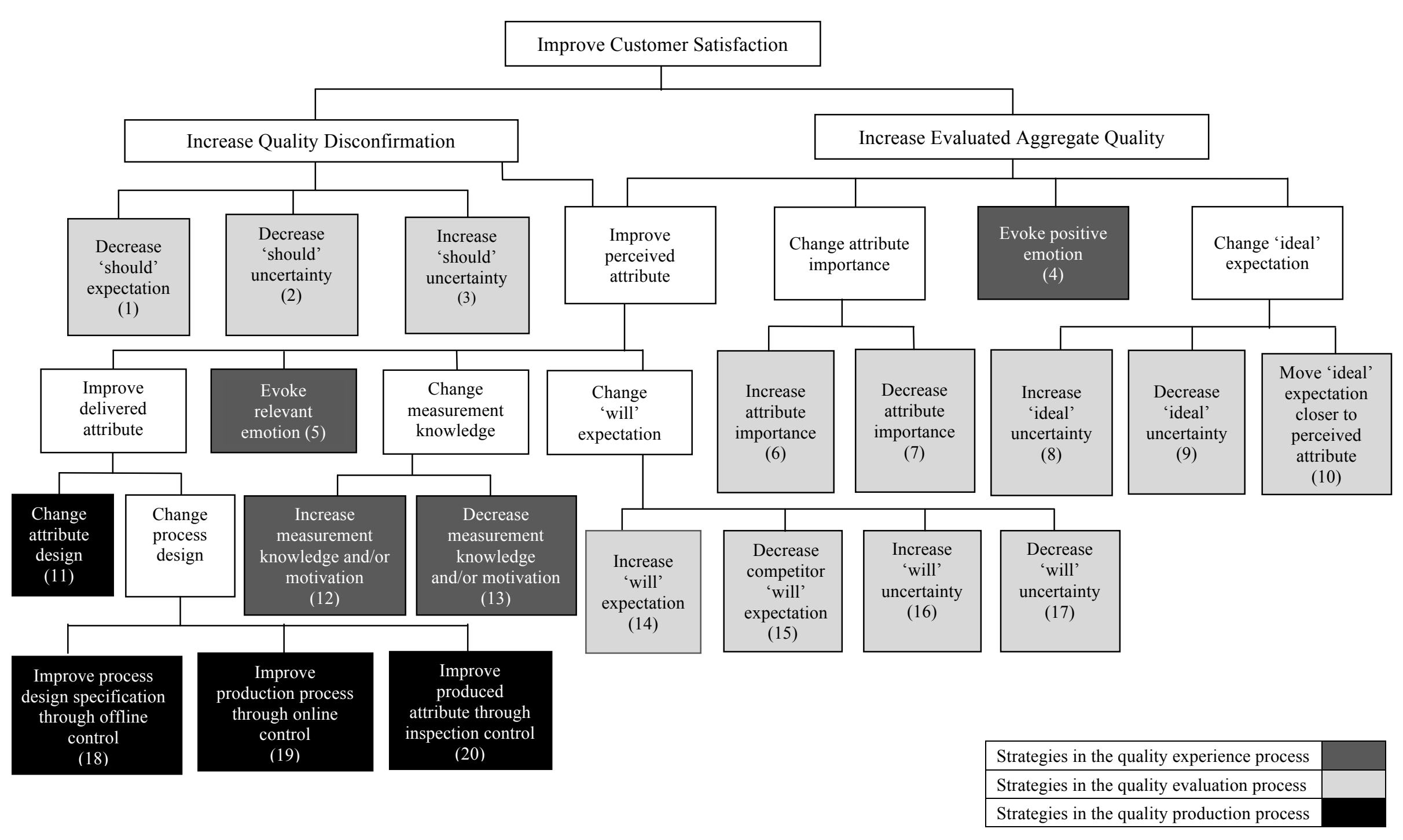

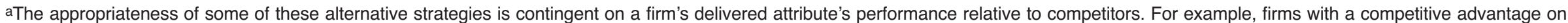

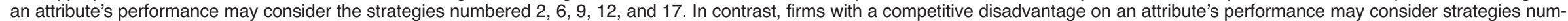
bered $3,7,8,13$, and 16 . 
1. Developing a comprehensive conceptual framework of quality that integrates the vast, multidisciplinary literature (see Figures 1 and 2 and Tables 1 and 2);

2. Illustrating the usefulness of our framework by offering new directions for theoretical and empirical research (see the "Implications for Theory" section, as well as Table 3 and the Appendix), proposing 20 strategies to improve customer satisfaction (Figure 3), and classifying Journal of Marketing and Management Science articles on quality published between 1988 and 2010 (Web Appendices B and C; http://www.marketingpower.com/jm_webappendix);

3. Postulating a quality experience process that occurs when firms deliver and customers perceive attributes as well as a set of customer-based factors that influence this process;

4. Offering a more complete view of the relationships between the three quality processes;

5. Describing three associated quality states that can be measured and managed by the firm;

6. Classifying an offering's attributes into three general types (universal, preference, idiosyncratic) based on measurement ambiguity and customer preference (Web Appendix A; http://www.marketingpower.com/jm_webappendix);

7. Linking 'will,' 'ideal,' and 'should' expectations within our proposed framework; and

8. Bringing customer emotion and co-production into a general framework of quality.

Although researchers and managers may disagree with some elements of our framework, we hope that any disagreements will lead to revising and building on our conceptualization. Quality is too important, and perhaps the topic most in need of a broad, integrative framework.

\section{Appendix \\ Measuring Key Constructs in the Integrative Quality Framework}

Our framework integrates several quality concepts developed in different research streams. Researchers have already developed valid and robust measures for some concepts: service quality (SERVQUAL; Parasuraman, Zeithaml, and Berry 1988), emotion (PANAS; Watson, Clark, and Tellegen 1988), and the production quality of engineering processes (Signal to Noise Ratio; Taguchi and Konishi 1993). In other cases, new scales should be developed. To that end, we offer both general and specific measurement advice.

In terms of general advice, researchers should typically provide information to the customer about the question's reference to attribute $\mathrm{x}$ of offering $\mathrm{y}$ in category $\mathrm{z}$. Exactly which of these elements will be relevant to any one question will vary. All measures examine "attribute x." If the measure varies across offerings within a category, we recommend examining "attribute x for offering y." However, if the measure varies across categories but not across offerings within a category, we recommend examining "attribute $\mathrm{x}$ in category z." 18 Table A1 offers illustrative measures of

18 For some measures, such as 'should' expectations, relative attribute importance, and importance of attribute information, category $z$ refers to the set of competing offerings (e.g., 5-star hotels) rather than the overall category (e.g., hotels). each concept. Next, while we use seven-point scales, the levels of these scales can be presented with descriptive anchors (e.g., $1=12$-inch seat vs. $7=24$-inch seat) or exemplars (e.g., relative to a card-table chair) to help customers calibrate their responses. Finally, there are some concepts that can be directly measured (e.g., attribute expectation), while others need to be computed or constructed based on two measures (e.g., experienced attribute quality $=$ the difference between 'ideal' expectation and delivered attribute performance).

In terms of specific advice, we suspect that researchers will have the greatest challenge developing measures for experienced attribute quality. One challenge with experienced attribute quality is that experts' assessments of delivered attribute performance may use one scale while customers' assessments of their ideal performance may use a different scale. For universal and preference attributes, experts may use a quantitative scale based on instrument measures. In contrast, customers may assess performance on a subjective scale (e.g., 1-7 scale). One approach to this challenge is to use measurement scales anchored by the lowest, middle, and highest instrument readings across the range of an attribute's performance. This approach would clarify the computation of the gap between delivered attribute performance and 'ideal' expectation. A second approach is for experts to convert their instrument measures to a 1-7 scale and then compute the gap with each customer's 1-7 'ideal' expectation rating. A third approach is to ask experts to evaluate the gap directly. This would require that experts are informed about each segment's 'ideal' expectation. Experts could then answer a question about how large the gap is between their assessment of delivered attribute performance and each segment's (or individual customer's) 'ideal' expectation. This approach is similar to Consumer Reports describing which offerings are best for certain types of customers or usage occasions. We advocate the first approach as best for understanding the inputs used to determine experienced attribute quality. However, we caution that this approach will face additional challenges when measuring idiosyncratic attributes.

The challenges of measuring idiosyncratic attributes are that (1) performance can be assessed only through human perceptions, thus using the anchored rating scales with performance levels based on instrument readings advocated above is not possible and (2) ideal performance levels vary across customers and experts. However, these challenges are not unique, and researchers may find inspiration in the large number of scales measuring constructs with these same characteristics. For example, researchers have measured personality (Kassarjian 1971), some dimensions of which could be viewed as idiosyncratic attributes of service providers (e.g., aggressiveness, sociability, emotional stability, personal relations, gregariousness). More recently, Aaker (1997) developed a brand personality scale measuring brand characteristics that could also be viewed as idiosyncratic attributes (e.g., sincerity, sophistication).

More broadly, to measure experienced attribute quality, we recommend that researchers develop scale items that can be used to assess both delivered attribute performance and customers' 'ideal' expectations. For example, using our air- 
TABLE A1

Illustrative Measures of Concepts in the Integrative Quality Framework

\begin{tabular}{|c|c|c|c|c|}
\hline Concept & Operationalization & What Is Measured & Source of Measure & Illustrative Measure \\
\hline \multirow[t]{3}{*}{$\begin{array}{l}\text { Produced attribute } \\
\text { quality }\end{array}$} & \multirow{3}{*}{$\begin{array}{l}\text { The gap between } \\
\text { produced attribute } \\
\text { performance and } \\
\text { attribute design } \\
\text { specification. }\end{array}$} & $\begin{array}{l}\text { Produced attribute } \\
\text { performance }\end{array}$ & Firm & $\begin{array}{l}\text { For universal and preference attributes, use an instrument measure of the performance } \\
\text { of attribute } x \text { for offering y (e.g., miles per gallon [MPG] for a car model). }\end{array}$ \\
\hline & & & $\begin{array}{l}\text { Firm (average } \\
\text { across experts) }\end{array}$ & $\begin{array}{l}\text { For idiosyncratic attributes, ask experts to rate the performance of attribute } x \text { for } \\
\text { offering y (seven-point scale where } 1=\text { "none" and } 7=\text { "very high"). }\end{array}$ \\
\hline & & $\begin{array}{l}\text { Attribute design } \\
\text { specification }\end{array}$ & Firm & $\begin{array}{l}\text { For universal and preference attributes, use an instrument measure of the specified } \\
\text { performance of attribute x for offering y (e.g., MPG for a car model). For idiosyncratic } \\
\text { attributes, ask managers for the specified performance of attribute x for offering y } \\
\text { (seven-point scale where } 1=\text { "none" and } 7=\text { "very high"). }\end{array}$ \\
\hline \multirow[t]{3}{*}{$\begin{array}{l}\text { Experienced } \\
\text { attribute quality }\end{array}$} & \multirow{3}{*}{$\begin{array}{l}\text { The gap between } \\
\text { delivered attribute } \\
\text { performance and } \\
\text { customer's 'ideal' } \\
\text { expectation. }\end{array}$} & $\begin{array}{l}\text { Delivered attribute } \\
\text { performance }\end{array}$ & Firm & $\begin{array}{l}\text { For universal and preference attributes, use an instrument measure of the performance } \\
\text { of attribute } \mathrm{x} \text { for offering y (e.g., MPG for a car model). }\end{array}$ \\
\hline & & & $\begin{array}{l}\text { Firm (average } \\
\text { across experts) }\end{array}$ & $\begin{array}{l}\text { For idiosyncratic attributes, ask experts to rate the performance of attribute } \mathrm{x} \text { for } \\
\text { offering y (seven-point scale where } 1=\text { "none" and } 7=\text { "very high"). }\end{array}$ \\
\hline & & $\begin{array}{l}\text { Attribute 'ideal' } \\
\text { expectation }\end{array}$ & Customer & $\begin{array}{l}\text { For universal and preference attributes, use an instrument measure of the customer's } \\
\text { ideal performance of attribute x in category z. When customers cannot provide } \\
\text { instrument measures for universal and preference attributes, use seven-point scales } \\
\text { and ask experts to convert customers' ratings to instrument measures. For idiosyncratic } \\
\text { attributes, ask customers to rate their ideal performance of attribute x in category z } \\
\text { (seven-point scale where } 1=\text { "none" and } 7 \text { = "very high"). a }\end{array}$ \\
\hline \multirow{3}{*}{$\begin{array}{l}\text { Evaluated } \\
\text { aggregate } \\
\text { quality }\end{array}$} & \multirow{3}{*}{$\begin{array}{l}\text { The gap between } \\
\text { perceived attribute } \\
\text { performance and } \\
\text { customer's 'ideal' } \\
\text { expectation. Gaps } \\
\text { are aggregated into } \\
\text { a weighted average } \\
\text { using customer's } \\
\text { relative importance } \\
\text { of each attribute. }\end{array}$} & $\begin{array}{l}\text { Perceived attribute } \\
\text { performance }\end{array}$ & Customer & $\begin{array}{l}\text { Ask customers to rate the performance of attribute } x \text { for offering y (seven-point scale } \\
\text { where } 1=\text { "none" and } 7=\text { "very high"). }\end{array}$ \\
\hline & & $\begin{array}{l}\text { Attribute 'ideal' } \\
\text { expectation }\end{array}$ & Customer & $\begin{array}{l}\text { For universal and preference attributes, use an instrument measure of the customer's } \\
\text { ideal performance of attribute x in category z. When customers cannot provide } \\
\text { instrument measures for universal and preference attributes, use seven-point scales } \\
\text { and ask experts to convert customers' ratings to instrument measures. For idiosyncratic } \\
\text { attributes, ask customers to rate their ideal performance of attribute x in category z } \\
\text { (seven-point scale where } 1=\text { "none" and } 7 \text { = "very high"). a }\end{array}$ \\
\hline & & $\begin{array}{l}\text { Relative attribute } \\
\text { importance }\end{array}$ & Customer & $\begin{array}{l}\text { Ask customers to rate the relative importance of attribute } x \text { in category } z \text { (constant sum } \\
\text { scale of } 100 \text { across attributes). }\end{array}$ \\
\hline \multirow[t]{2}{*}{ Attribute type } & $\begin{array}{l}\text { Measurement } \\
\text { ambiguity is } \\
\text { whether an } \\
\text { instrument exists } \\
\text { to measure an } \\
\text { attribute's } \\
\text { performance. }\end{array}$ & $\begin{array}{l}\text { Measurement } \\
\text { ambiguity }\end{array}$ & Firm & $\begin{array}{l}\text { Ask managers whether the performance of attribute } x \text { can be measured with an } \\
\text { available instrument (Yes, No). }\end{array}$ \\
\hline & $\begin{array}{l}\text { Customer } \\
\text { preference } \\
\text { heterogeneity is the } \\
\text { variance of 'ideal' } \\
\text { expectations. }\end{array}$ & $\begin{array}{l}\text { Customer } \\
\text { preference } \\
\text { heterogeneity }\end{array}$ & $\begin{array}{l}\text { Customers } \\
\text { (variance across } \\
\text { customers) }\end{array}$ & $\begin{array}{l}\text { Ask customers to rate their 'ideal' performance of attribute } \mathrm{x} \text { in category z (seven-point } \\
\text { scale where } 1=\text { "none" and } 7 \text { = "very high"). }\end{array}$ \\
\hline
\end{tabular}


TABLE A1

Continued

.

\section{Concept}

Measurement

knowledge $^{b}$

Operationalization What Is Measured Source of Measure

Extent to which

customer has

knowledge to

accurately

assess attribute

performance.

Measurement motivation

\section{Extent to which}

accuracy of

attribute perfor-

mance measure-

ment is important

to customer.

Attribute 'will'

expectation and

'will' uncertainty

ribute perfor-

believes an

offering is going to

deliver and the

variance around

that performance.

Attribute 'ideal'

Attribute perfor-

expectation and mance a customer

'ideal' uncertainty desires in a cate-

gory's offerings and

the variance around

that performance.

Attribute 'should'

expectation

and 'should'

uncertainty

Attribute perfor-

mance a customer

believes a cate-

gory's offerings

ought to deliver and

Attribute

knowledge

Customer

Administer an attribute measurement knowledge test that asks customers to assess
attribute performance of attribute $\mathrm{x}$ in category $\mathrm{z}$. Score the accuracy of this assessment.

$\begin{aligned} & \text { Attribute } \\ & \text { importance }\end{aligned}$
Customer $\begin{aligned} & \text { Ask customers to rate the importance of knowing the performance of attribute } x \text { in } \\ & \text { category z (seven-point scale where } 1=\text { "none" and } 7=\text { "very high"). }\end{aligned}$

Attribute 'will' $\quad$ Customer $\quad$ Ask customers to rate the performance that will be provided by attribute $\mathrm{x}$ for offering $\mathrm{y}$ expectation

Attribute 'will' uncertainty

Attribute 'ideal' expectation

Attribute 'ideal' uncertainty

\section{Attribute 'should'} expectation

Attribute 'should' uncertainty (seven-point scale where $1=$ "none" and 7 = "very high").

Customer

Ask customers to rate how confident they are about their predicted performance of attribute $\mathrm{x}$ for offering y (seven-point scale where $1=$ "not at all confident" and $7=$

Customer

Ask customers to rate their ideal performance of attribute $\mathrm{x}$ in category $\mathrm{z}$ (seven-point scale where 1 = "none" and 7 = "very high").c

Customer

Ask customers to rate how confident they are about their ideal performance of attribute $x$ in category z (seven-point scale where 1 = "not at all confident" and 7 = "very confident").

Customer

Ask customers to rate the performance that should be provided by attribute $\mathrm{x}$ in category z (seven-point scale where $1=$ "none" and 7 = "very high").c

Customer

Ask customers to rate how confident they are about the performance that should be provided by attribute $\mathrm{x}$ in category $\mathrm{z}$ (seven-point scale where 1 = "not at all confident" and 7 = "very confident"). "very confident").

that performance.

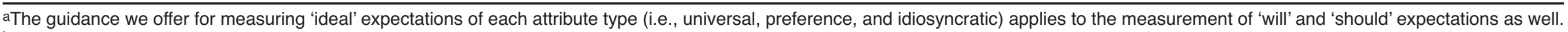

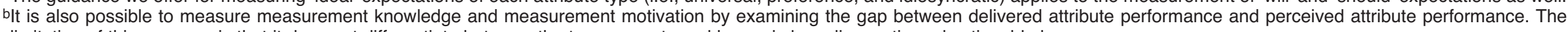
limitation of this measure is that it does not differentiate between the two concepts and hence is less diagnostic and actionable by managers.

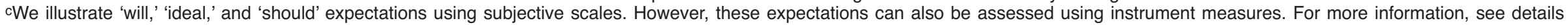
under "Attribute 'ideal' expectation" on the first page of Table A1. 
line example, the courtesy of fellow passengers could be assessed by developing an inventory of traits and behaviors associated with passenger courtesy. Experts could then measure the levels of these traits and behaviors and assess customers' ideal levels. One challenge occurs when expert evaluations of passenger courtesy are influenced by experts' own ideal preferences. Therefore, firms should ensure their experts are aware of the range of customers' ideal courtesy levels. Firms could also average across experts who hold different ideal courtesy levels. An alternative direct approach for evaluating courtesy is to ask experts to assess the gaps between customers' 'ideal' expectations and delivered attribute performance. However, when the gap changes, it will not be clear whether a change in 'ideal' expectation or delivered attribute performance is driving the change. Furthermore, this approach will lose validity when experts substitute their own ideal for customers' ideals.

Table A1 provides a starting point for scale development of the three quality states and related concepts. It offers an operationalization of each concept, a description of what is measured, the source of each measure, and illustrative measures.

\section{REFERENCES}

Aaker, Jennifer L. (1997), "Dimensions of Brand Personality," Journal of Marketing Research, 34 (August), 347-56.

Akerlof, George A. (1970), "The Market for 'Lemons': Quality Uncertainty and the Market Mechanism," Quarterly Journal of Economics, 84 (3), 488-500.

Anderson, Eugene W., Claes Fornell, and Donald R. Lehmann (1994), "Customer Satisfaction, Market Share, and Profitability: Findings from Sweden," Journal of Marketing, 58 (July), 53-66.

— and Mary W. Sullivan (1993), "The Antecedents and Consequences of Customer Satisfaction for Firms," Marketing Science, 12 (2), 125-43.

Arnould, Eric J. and Linda L. Price (1993), "River Magic: Extraordinary Experience and the Extended Service Encounter," Journal of Consumer Research, 20 (1), 24-45.

Barney, Jay (1991), "Firm Resources and Sustained Competitive Advantage," Journal of Management, 17 (1), 99-120.

Bendapudi, Neeli and Robert P. Leone (2003), "Psychological Implications of Customer Participation in Co-Production," Journal of Marketing, 67 (January), 14-28.

Bettencourt, Lance A. (1997), "Customer Voluntary Performance: Customers as Partners in Service Delivery," Journal of Retailing, 73 (3), 383-406.

Bitner, Mary Jo, William T. Faranda, Amy R. Hubbert, and Valarie Zeithaml (1997), "Customer Contributions and Roles in Service Delivery," International Journal of Service Industry Management, 8 (3), 193-205.

Bolton, Ruth N. and James H. Drew (1991), "A Longitudinal Analysis of the Impact of Service Changes on Customer Attitudes," Journal of Marketing, 55 (January), 1-9.

_ and Katherine N. Lemon (1999), "A Dynamic Model of Customers' Usage of Services: Usage as an Antecedent and Consequence of Satisfaction," Journal of Marketing Research, 36 (May), 171-86.

,-- , and Peter C. Verhoef (2008), "Expanding Businessto-Business Customer Relationships: Modeling the Customer's Upgrade Decision," Journal of Marketing, 72 (January), 46-64.

— and S. Saxena-Iyer (2009), "Interactive Services: A Framework, Synthesis and Research Directions," Journal of Interactive Marketing, 23 (1), 91-104.

Boulding, William, Ajay Kalra, and Richard Staelin (1999), "The Quality Double Whammy," Marketing Science, 18 (4), 463-84.

— $-\ldots, \ldots$, and Valarie A. Zeithaml (1993), “A Dynamic Process Model of Service Quality: From Expectations to Behavioral Intentions," Journal of Marketing Research, 30 (February), 7-27.

Brady, Michael K. and Joseph Cronin Jr. (2001), "Some New Thoughts on Conceptualizing Perceived Service Quality: A Hierarchical Approach," Journal of Marketing, 65 (July), 34-49.
Brucks, Merrie, Valarie A. Zeithaml, and Gillian Naylor (2000), "Price and Brand Name as Indicators of Quality Dimensions for Consumer Durables," Journal of the Academy of Marketing Science, 28 (3), 359-74.

Buzzell, Robert D. and Bradley T. Gale (1987), The PIMS Principles: Linking Strategy to Performance. New York: The Free Press.

Cadotte, Ernest R., Robert B. Woodruff, and Roger L. Jenkins (1987), "Expectations and Norms in Models of Consumer Satisfaction," Journal of Marketing Research, 24 (August), $305-314$

Churchill, Gilbert A., Jr., and Carol Surprenant (1982), “An Investigation into the Determinants of Customer Satisfaction," Journal of Marketing Research, 19 (November), 491-504.

Cohen, Joel, Michael Tuan Pham, and Eduardo Andrade (2008), "The Nature and Role of Affect in Consumer Behavior," in Handbook of Consumer Psychology, Curtis P. Haugtvedt, Paul M. Herr, and Frank R. Kardes, eds. New York: Lawrence Erlbaum Associates, 297-348.

Coyne, Kevin (1989), "Beyond Service Fads-Meaningful Strategies for the Real World," Sloan Management Review, 30 (4), 69-76.

Cronin, J. Joseph, Jr., and Steven A. Taylor (1992), "Measuring Service Quality: A Reexamination and Extension," Journal of Marketing, 56 (July), 55-68.

— and - (1994), "SERVPERF Versus SERVQUAL: Reconciling Performance-Based and Perceptions-Minus-Expectations Measurement of Service Quality," Journal of Marketing, 58 (January), 125-31.

Dalton, Dan R., William D. Todor, Michael J. Spendolini, Gordon J. Fielding, and Lyman W. Porter (1980), "Organization Structure and Performance: A Critical Review," Academy of Management Review, 5 (1), 49-64.

Darby, Michael R. and Edi Karni (1973), "Free Competition and the Optimal Amount of Fraud," Journal of Law and Economics, 16 (1), 67-88.

Deming, W. Edwards (1982), Quality, Productivity, and Competitive Position. Cambridge, MA: MIT Press.

Desai, Preyas S. (2001), "Quality Segmentation in Spatial Markets: When Does Cannibalization Affect Product Line Design?" Marketing Science, 20 (3), 265-83.

Dewey, John (1938), Experience and Education. New York: Collier Books.

Ding, Jie, Betsy S. Greenberg, and Hirofumi Matsuo (1998), "Repetitive Testing Strategies When the Testing Process Is Imperfect," Management Science, 44 (10), 1367-78.

Erdem, Tülin and Michael P. Keane (1996), "Decision-Making Under Uncertainty: Capturing Dynamic Brand Choice Processes in Turbulent Consumer Goods Markets," Marketing Science, 15 (1), 1-20.

Feigenbaum, Armand V. (1991), Total Quality Control, 3d ed. New York: McGraw-Hill. 
Fornell, Claes (1995), “The Quality of Economic Output: Empirical Generalizations about Its Distribution and Relationship to Market Share," Marketing Science, 14 (3), Part 2 of 2: Special Issue on Empirical Generalizations in Marketing (1995), pp. G203-G211.

—, Michael D. Johnson, Eugene W. Anderson, Jaesung Cha, and Barbara Everitt Bryant (1996), "The American Customer Satisfaction Index: Nature, Purpose, and Findings," Journal of Marketing, 60 (October), 7-18.

Garvin, David A. (1984), “What Does 'Product Quality’ Really Mean?" Sloan Management Review, 26 (1), 25-43.

Gong, Linguo, Wushong Jwo, and Kwei Tang (1997), "Using Online Sensors in Statistical Process Control," Management Science, 43 (7), 1017-28.

Green, Paul E. and V. Srinivasan (1990), "Conjoint Analysis in Marketing: New Developments with Implications for Research and Practice," Journal of Marketing, 54 (October), 3-19.

Griffin, Abbie and John R. Hauser (1993), "The Voice of the Customer," Marketing Science, 12 (1), 1-27.

Hamada, Michael, Robert J. Mackay, and James B. Whitney (1993), "Continuous Process Improvement with Observational Studies," Journal of Quality Technology, 25 (2), 77-84.

Hauser, John R. and Don Clausing (1988), "The House of Quality," Harvard Business Review, 66 (3), 63-73.

Hellofs, Linda L. and Robert Jacobson (1999), "Market Share and Customers' Perceptions of Quality: When Can Firms Grow Their Way to Higher Versus Lower Quality?" Journal of Marketing, 63 (January), 16-25.

Hennig-Thurau, Thorsten, Markus Groth, Michael Paul, and Dwayne D. Gremler (2006), "Are All Smiles Created Equal? How Emotional Contagion and Emotional Labor Affect Service Relationships," Journal of Marketing, 70 (July), 58-73.

Hoch, Stephen J. and John Deighton (1989), "Managing What Consumers Learn from Experience," Journal of Marketing, 53 (April), 1-20.

Holbrook, Morris B. and Kim P. Corfman (1985), "Quality and Value in the Consumption Experience: Phaedrus Rides Again," in Perceived Quality, Jacob Jacoby and Jerry C. Olson, eds. Lexington, MA: Lexington Books, 31-57.

Homburg, Christian, Nicole Koschate, and Wayne D. Hoyer (2005), "Do Satisfied Customers Really Pay More? A Study of the Relationship Between Customer Satisfaction and Willingness to Pay," Journal of Marketing, 69 (April), 84-96.

Hotelling, Harold (1929), "Stability in Competition," The Economic Journal, 39 (153), 41-57.

Huang, Peng, Nicholas H. Lurie, and Sabyasachi Mitra (2009), "Searching for Experience on the Web: An Empirical Examination of Consumer Behavior for Search and Experience Goods," Journal of Marketing, 73 (March), 55-69.

Juran, Joseph M. (1992), Juran on Quality by Design: The New Steps for Planning Quality into Goods and Services. New York: The Free Press.

Kackar, R.N. (1985), “Off-Line Quality Control, Parameter Design, and the Taguchi Method," Journal of Quality Technology, 17 (October), 176-88.

Kahn, Barbara E. and Brian Wansink (2004), “The Influence of Assortment Structure on Perceived Variety and Consumption Quantities," Journal of Consumer Research, 30 (4), 519-33.

Karmarkar, Uday S. (1996), "Integrative Research in Marketing and Operations Management," Journal of Marketing Research, 33 (May), 125-33.

_ and Uday M. Apte (2007), "Operations Management in the Information Economy: Information Products, Processes, and Chains," Journal of Operations Management, 25 (2), 438-53.

Kassarjian, Harold H. (1971), "Personality and Consumer Behavior: A Review," Journal of Marketing Research, 8 (November), 409-420.
Kelley, Scott W., James H. Donnelly Jr., and Steven J. Skinner (1990), "Customer Participation in Service Production and Delivery," Journal of Retailing, 66 (3), 315-35.

Kennedy, Paul (1987), The Rise and Decline of Great Powers: Economic Change and Military Conflict from 1500-2000. New York: Random House.

Kirmani, Amna and Akshay R. Rao (2000), "No Pain, No Gain: A Critical Review of the Literature on Signaling Unobservable Product Quality," Journal of Marketing, 64 (April), 66-79.

Kolb, David A. (1984), Experiential Learning: Experience as the Source of Learning and Development. Upper Saddle River, NJ: Prentice Hall.

Kopalle, Praveen K. and Donald R. Lehmann (2001), "Strategic Management of Expectations: The Role of Disconfirmation Sensitivity and Perfectionism," Journal of Marketing Research, 38 (August), 386-94.

Kordupleski, Raymond E., Roland T. Rust, and Anthony J. Zahorik (1993), "Why Improving Quality Doesn't Improve Quality (or Whatever Happened to Marketing?)," California Management Review, 35 (3), 82-95.

Kumar, Piyush, Manohar U. Kalwani, and Maqbool Dada (1997), "The Impact of Waiting Time Guarantees on Customers' Waiting Experiences," Marketing Science, 16 (4), 295-314.

Lengnick-Hall, Cynthia A. (1996), "Customer Contributions to Quality: A Different View of the Customer-Oriented Firm," Academy of Management Review, 21 (3), 791-824.

Loewenstein, George (1996), "Out of Control: Visceral Influences on Behavior," Organizational Behavior and Human Decision Processes, 65 (3), 272-92.

MacInnis, Deborah J., Christine Moorman, and Bernard Jaworski (1991), "Enhancing and Measuring Consumers' Motivation, Opportunity to Process Brand Information from Ads," Journal of Marketing, 55 (October), 32-53.

Mayer, Kyle J., Jack A. Nickerson, and Hideo Owan (2004), “Are Supply and Plant Inspections Complements or Substitutes? A Strategic and Operational Assessment of Inspection Practices in Biotechnology," Management Science, 50 (8), 1064-81.

Menon, Kalyani and Laurette Dubé (2007), "The Effect of Emotional Provider Support on Angry Versus Anxious Consumers,' International Journal of Research in Marketing, 24 (3), 268-75.

Meuter, Matthew L., Amy L. Ostrom, Robert I. Roundtree, and Mary Jo. Bitner (2000), "Self-Service Technologies: Understanding Customer Satisfaction with Technology-Based Service Encounters," Journal of Marketing, 64 (July), 50-64.

Mitra, Debanjan and Peter N. Golder (2006), "How Does Objective Quality Affect Perceived Quality? Short-Term Effects, Long-Term Effects, and Asymmetries," Marketing Science, 25 (3), 230-47.

Montgomery, Douglas C. (2008), Introduction to Statistical Quality Control, 6th ed. New York: John Wiley \& Sons.

Morgan, Neil A. and Douglas W. Vorhies (2001), "Product Quality Alignment and Business Unit Performance," Journal of Product Innovation Management, 18 (6), 396-407.

Nelson, Philip (1970), "Information and Consumer Behavior," Journal of Political Economy, 78 (2), 311-29.

Oliver, Richard L. (1980), "A Cognitive Model of the Antecedents and Consequences of Satisfaction Decisions," Journal of Marketing Research, 17 (November), 460-69.

(1996), Satisfaction: A Behavioral Perspective on the Consumer. New York: McGraw-Hill.

(2009), Satisfaction: A Behavioral Perspective on the Consumer. New York: M.E. Sharpe.

- and John E. Swan (1989), "Equity and Disconfirmation Perceptions as Influences on Merchant and Product Satisfaction," Journal of Consumer Research, 16 (3), 372-83. 
Parasuraman, A., Leonard L. Berry, and Valarie A. Zeithaml (1991), "Understanding Customer Expectations of Service," Sloan Management Review, 32 (3), 39-48.

, Valarie A. Zeithaml, and Leonard L. Berry (1985), "A Conceptual Model of Service Quality and Its Implications for Future Research," Journal of Marketing, 49 (October), 41-50.

- —, and — (1988), "SERVQUAL: Multiple-Item Scale for Measuring Consumer Perceptions of Service Quality," Journal of Retailing, 64 (1), 12-40.

—, _ and - (1994), "Reassessment of Expectations as a Comparison Standard in Measuring Service Quality: Implications for Further Research," Journal of Marketing, 58 (January), 111-24.

Petty, Richard E. and John T. Cacioppo (1986), Communication and Persuasion: Central and Peripheral Routes to Attitude Change. New York: Springer-Verlag.

Pirsig, Robert M. (1974), Zen and the Art of Motorcycle Maintenance: An Inquiry into Values. New York: HarperTorch.

Porter, Michael E. (1998), Competitive Advantage: Creating and Sustaining Superior Performance. New York: The Free Press.

Powell, Thomas C. (1995), "Total Quality Management as Competitive Advantage: A Review and Empirical Study," Strategic Management Journal, 16 (1), 15-37.

Price, Linda L. and Eric J. Arnould (1999), "Commercial Friendships: Service Provider-Client Relationships in Context," Journal of Marketing, 63 (October), 38-56.

,-- , and Patrick Tierney (1995), "Going to Extremes: Managing Service Encounters and Assessing Provider Performance," Journal of Marketing, 59 (April), 83-97.

Reeves, Carol A. and David A. Bednar (1994), "Defining Quality: Alternatives and Implications," Academy of Management Review, 19 (3), 419-45.

Rust, Roland T., J. Jeffrey Inman, Jianmin Jia, and Anthony Zahorik (1999), "What You Don't Know About Customer-Perceived Quality: The Role of Customer Expectation Distributions," Marketing Science, 18 (1), 77-92.

—_ Christine Moorman, and Peter R. Dickson (2002), "Getting Return on Quality: Revenue Expansion, Cost Reduction, or Both?" Journal of Marketing, 66 (October), 7-24.

—_ Anthony J. Zahorik, and Timothy L. Keiningham (1995), "Return on Quality (ROQ): Making Service Quality Financially Accountable," Journal of Marketing, 59 (April), 58-70.

Salop, Steven C. (1979), "Monopolistic Competition with Outside Goods," Bell Journal of Economics, 10 (1), 141-56.
Shewhart, Walter A. (1986), Statistical Method from the Viewpoint of Quality Control. New York: Dover.

Spence, A. Michael (1975), "Monopoly, Quality, and Regulation," Bell Journal of Economics, 6 (2), 417-29.

Steenkamp, Jan-Benedict E.M. (1990), "Conceptual Model of the Quality Perception Process," Journal of Business Research, 21 (4), 309-333.

Sutton, John (1986), "Vertical Product Differentiation: Some Basic Themes," American Economic Review, 76 (2), 393-98.

Taguchi, G. and S. Konishi (1993), Taguchi Methods: Signal-toNoise Ratio for Quality Evaluation, Quality Engineering Series, Vol. 3. Homewood, IL: Richard D. Irwin.

Tellis, Gerard J. and Joseph Johnson (2007), "The Value of Quality," Marketing Science, 26 (6), 758-73.

_ and Birger Wernerfelt (1987), "Competitive Price and Quality Under Asymmetric Information," Marketing Science, 6 (3), 240-53.

Tirole, Jean (1988), The Theory of Industrial Organization. Cambridge, MA: MIT Press.

Tse, David K. and Peter C. Wilton (1988), "Models of Consumer Satisfaction Formation: An Extension," Journal of Marketing Research, 25 (May), 204-212.

Watson, David, Lee Anna Clark, and Auke Tellegen (1988), "Development and Validation of Brief Measures of Positive and Negative Affect: The PANAS Scales," Journal of Personality and Social Psychology, 54 (6), 1063-70.

Woodall, William H. and Douglas C. Montgomery (1999), "Research Issues and Ideas in Statistical Process Control," Journal of Quality Technology, 31 (4), 376-86.

Woodruff, Robert B., Ernest R. Cadotte, and Roger L. Jenkins (1983), "Modeling Consumer Satisfaction Processes Using Experience-Based Norms," Journal of Marketing Research, 20 (August), 286-304.

Zeithaml, Valarie A. (1988), "Consumer Perceptions of Price, Quality, and Value: A Means-End Model and Synthesis of Evidence," Journal of Marketing, 52 (July), 2-22.

_, Leonard L. Berry, and A. Parasuraman (1988), "Communication and Control Processes in the Delivery of Service Quality," Journal of Marketing, 52 (April), 35-48.

—, _ and _ (1993), "The Nature and Determinants of Customer Expectations of Service," Journal of the Academy of Marketing Science, 21 (1), 1-12.

— - , and (1996), "The Behavioral Consequences of Service Quality," Journal of Marketing, 60 (April), 31-46. 
Copyright of Journal of Marketing is the property of American Marketing Association and its content may not be copied or emailed to multiple sites or posted to a listserv without the copyright holder's express written permission. However, users may print, download, or email articles for individual use. 